\title{
Vibration Responses of Rotor Systems in Diesel Multiple Units under Dynamic Spatial Misalignments and Base Motions
}

\author{
Kun Wu ${ }^{\mathrm{a}}$, Zhiwei Liu ${ }^{\mathrm{a}}$, Qian Ding ${ }^{\mathrm{a}, \mathrm{b}, *}$, Philip Shackleton ${ }^{\mathrm{c}}$, Robert Cattley ${ }^{\mathrm{c}}$, Fengshou Gu${ }^{\mathrm{c}}$, Andrew D.Ball, \\ ${ }^{a}$ Department of Mechanics, Tianjin University, Tianjin, 300350, China \\ b Tianjin Key Laboratory of Nonlinear Dynamics and Control, Tianjin, 300350, China \\ c School of Computing and Engineering, University of Huddersfield, Huddersfield, HD1 3DH, UK
}

\begin{abstract}
To achieve high performance monitoring of the electric transmission powerpack for a Diesel Multiple Unit (DMU), the dynamic responses of the rotor system inside the powerpack with Dynamic Spatial Misalignment (DSM) and base motions from car body are investigated through structural modeling and numerical analysis. A three-dimensional coupled model, including public framework, diesel engine, electric generator and rotor system, is developed. Vibrations under deterministic and random base motions are numerically calculated using the Newmark Method. The simulation results show that vibration responses of the coupled model are evidently different from those of rotors with a fixed base. DSM is more nonlinearly sensitive to the deterministic base motion than rotor vibrations, and the converse is true when the base pitch motion in is random in frequency. Additionally, results show that DSM may vary significantly in different axial positions, with large base motions in some extreme situations. These findings lay the primary foundations for implementing vibration-based condition monitoring of DMU diesel-generator systems.
\end{abstract}

Keywords: rotor dynamics; dynamic spatial misalignment; base motions; nonlinear vibration

\section{Introduction}

A Diesel Multiple Unit (DMU) is a self-propelled rail car, which includes both a passenger carriage and propulsion, in the form of diesel engines [1]. There are two common types of transmission in DMUs: hydraulic transmission and electric transmission [2]. The rotor system studied here, is a crucial component of an electric transmission powerpack, in which a diesel engine drives a generator through an elastic coupling. The powerpack itself is a part of a modular powertrain that contains some type of engine, a transmission and various auxiliary components.

Railway vehicles operate under a broad spectrum of external excitations. Chen et al. [3] investigated the dynamic characteristics of a locomotive-track coupled system in the vertical direction, through a twodimensional model. External excitations came from periodic rail geometric irregularity and the time-varying mesh stiffness of the gear pairs. From this work, the modulation phenomenon between the track and transmission vibrations was evident. A three-dimensional locomotive-track coupled model was developed by Zhang et al. [4], and numerical simulation was carried using the Hertz nonlinear elastic theory for calculations of the wheel-rail contact forces. The model was validated by field tests in the time and timefrequency domains. Wang et al. [5] presented a new iterative method to obtain the equations of motion of the moving vehicle and the two-layer flexible track subsystems separately, and nonlinear wheel rail forces were included. Gu and Choi [6] studied the dynamic response of rail support, and indicated that the difference between natural frequencies of the train suspension and track means that the dynamic response of the track was largely independent of the dynamic properties of the trains. A new model [7], considering flexible deflection of shaft and bearing, time-varying nonlinear contact and track irregularity was established, and the author found that the dynamic responses of the wheelset-bearing system were considerably affected by

\footnotetext{
* Corresponding author

E-mail address: qding@tju.edu.cn (Qian Ding)
} 
track irregularities.

Chen et al. [8] indicated that rotor systems in vehicles or trains should be considered with a moving base. Extensive research has been undertaken focusing on rotor dynamics under base excitations. Lee et al. [9] focused on the transient responses of a rotor-bearing system under base-transferred shock force, and found them sensitive to the duration of the shocks. Qiu et al. [10] proposed and validated a rotational-translationalaxial dynamic model of the planetary gear under pitching base motion, and found that pitching base motion could bring in extra parametric and forced excitation frequencies. El-Saeidy and Sticher [11] presented a formulation, which considered the linear/nonlinear spring characteristics of the support bearings, to analyse the dynamic responses of rigid rotors subject to base excitations. To obtain the nonlinear dynamic characteristics of the rotor-bearing system subjected to a harmonic ground motion, Phadatare et al. [12] introduced the higher-order Euler-Bernoulli deformation theorem into consideration. The presented nonlinear model was validated and found to be accurate enough to calculate the correct value of critical speeds and dynamic responses.

Coupling misalignment has been the most common fault after unbalance in rotating machines, and represents over $50 \%$ of faults in rotating machinery (according to incomplete statistics) [13]. Guo [14] developed a novel analytic model to analyze contact conditions between meshing teeth and found that reaction forces of gear couplings were functions of misalignment, friction and torque. El-Mongy and Younes [15] analyzed vibrational transient response of a cracked rotor in the presence of unbalance and coupling misalignment. Liu et al studied the torsional vibration and torque fluctuation of the coupling due to diesel engine misfire [16] and the transient vibration response of angular misaligned rotors with rubbing effect during speed-up process [17].

Those articles have paved theoretical and experimental basis to achieve vibration detection and monitoring of rotor systems in a railway vehicle. However, there are few researchers working on dynamic characteristics of misaligned rotors with base motions. The main object of this paper, is to obtain the nonlinear dynamic responses of a coupled system, composing of public framework, diesel engine, electric generator and rotors, under Dynamic Spatial Misalignment effects and base motions from car body.

\section{Powerpack Spatial Dynamics Model}

\subsection{Physical Model}

The diesel engine (i.e. engine denoted with subscript $e$ ) and electric generator (i.e. generator denoted with subscript $g$ ), together with other auxiliary equipment (shown in Fig.1), are installed under the car floor and hung elastically to the public framework (i.e. subscript $p f$ ) through first stage isolators (i.e. subscript $f i$ ) [18], while there are second stage isolators (i.e. subscript si) between car body and the public framework. The schematic of the powerpack is shown in Fig.2. 


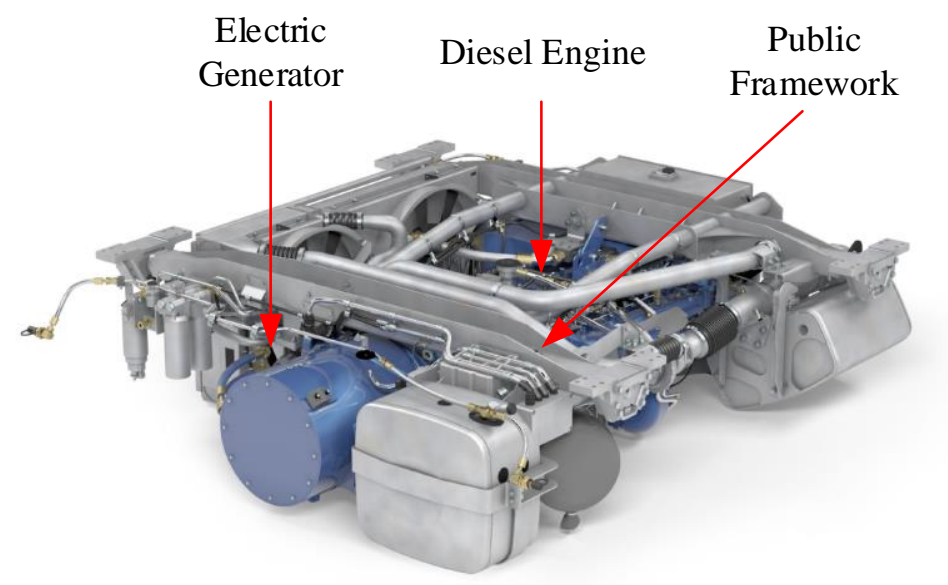

Fig.1 The Voith Powerpack

There are 3 rigid bodies in the powerpack system, including public framework, engine and generator. Total 15 degrees of freedom (DOF) are considered, which are lateral $(Y)$, bounce $(Z)$, roll $(\varphi)$, pitch $(\beta)$ and yaw $(\psi)$ motions for each rigid body, while vibrations in the longitudinal direction $(X)$ are negligible compared to other directions in practice, thus not considered.

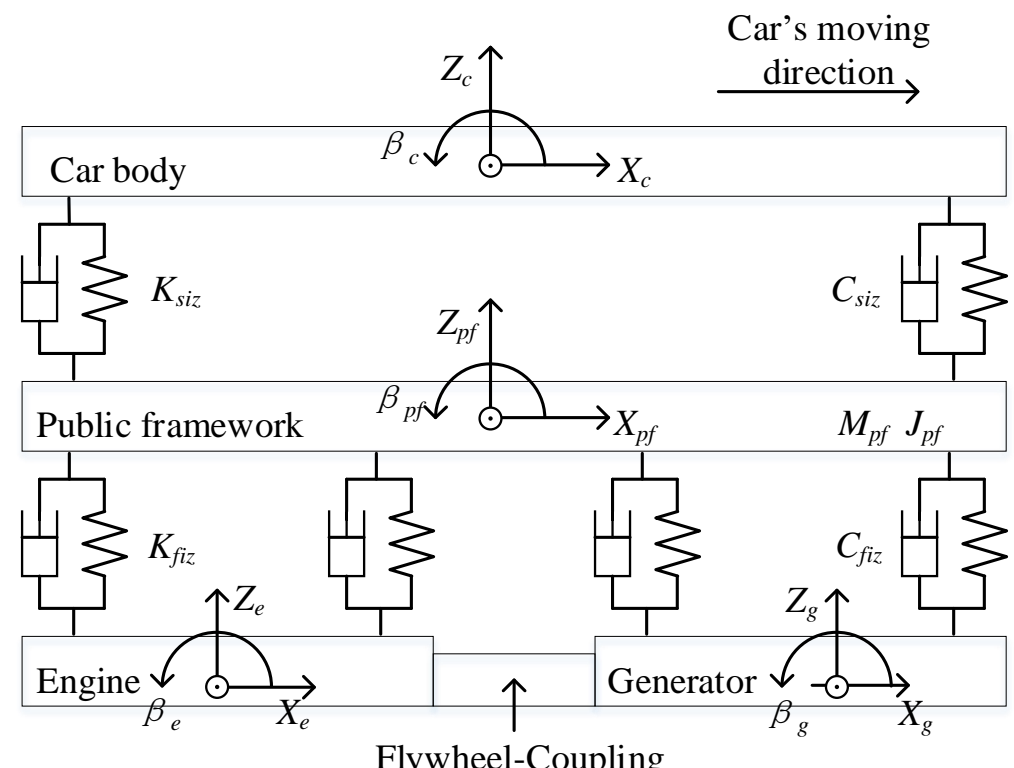

(a) Front view 


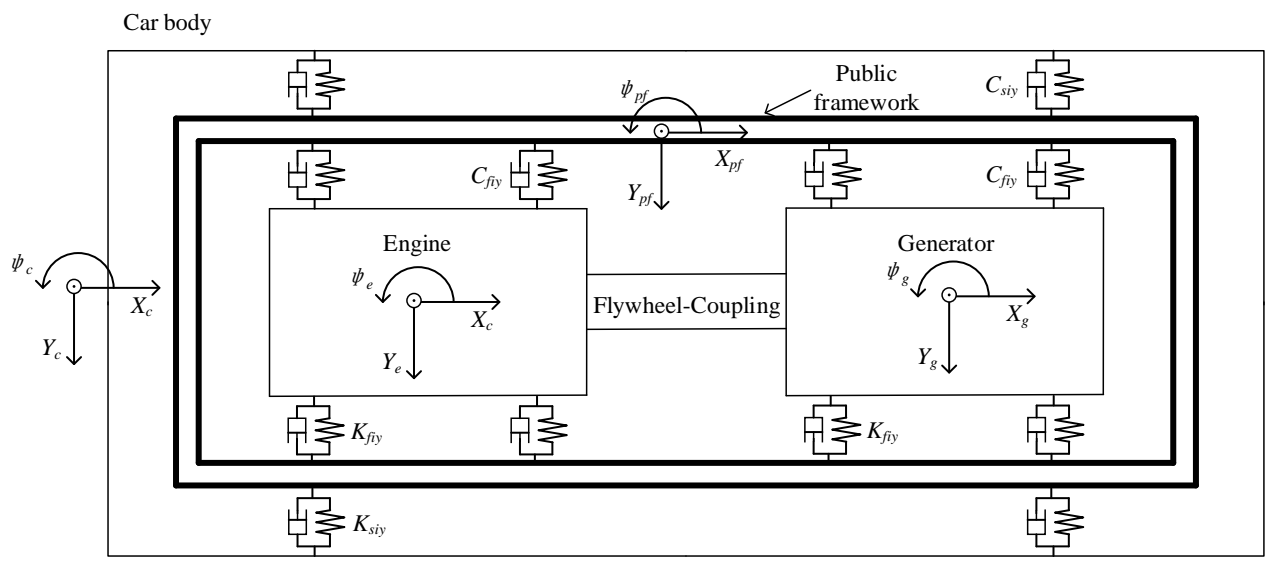

(b) Top view

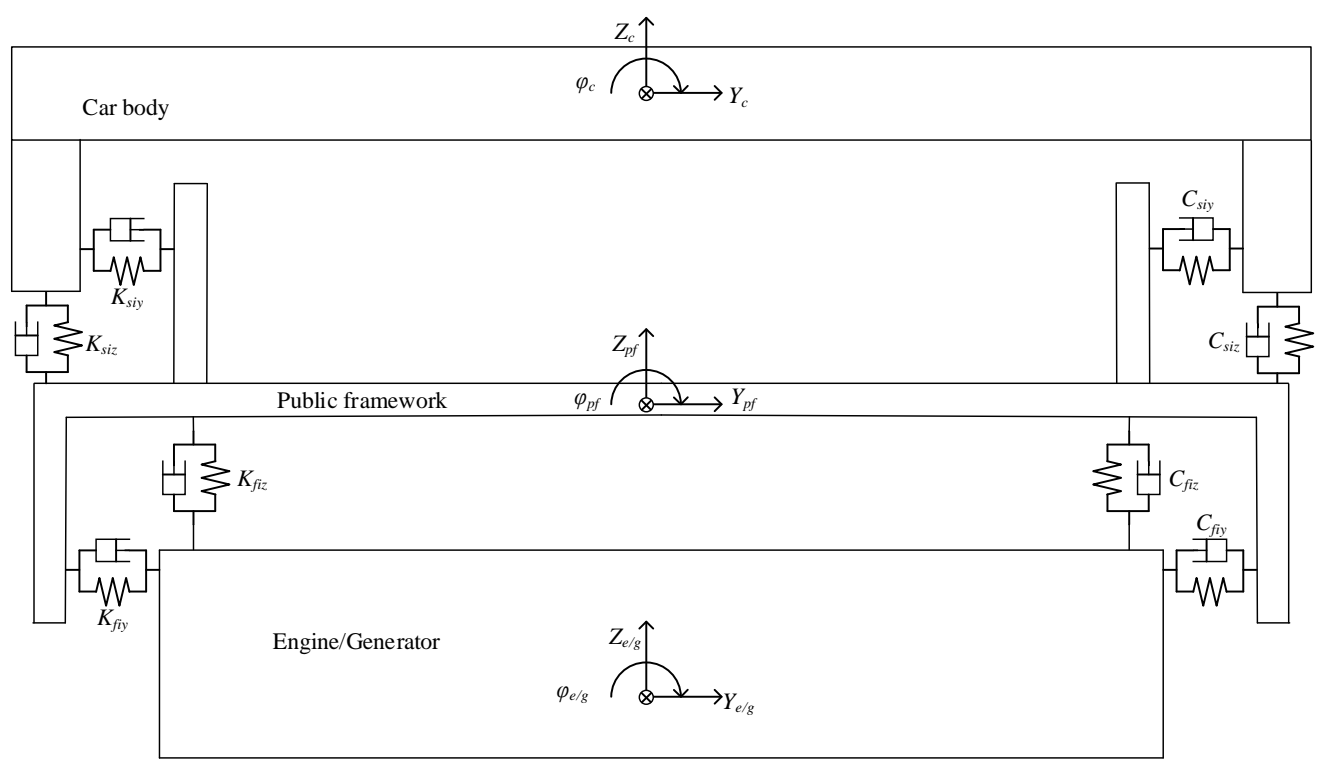

(c) Back view

Fig.2 Schematics of the powerpack

The elastic rotors are elastically supported inside engine/generator, as shown in Fig.3. The overhung disks in Fig.3a are the flywheel of the engine, and the elastic coupling connected to the generator respectively. Torque and torsional motion are transmitted from engine to generator through engaged flywheel and coupling. DSM will appear at the elastic coupling, while the car body will move in deterministic and random ways at given rates.

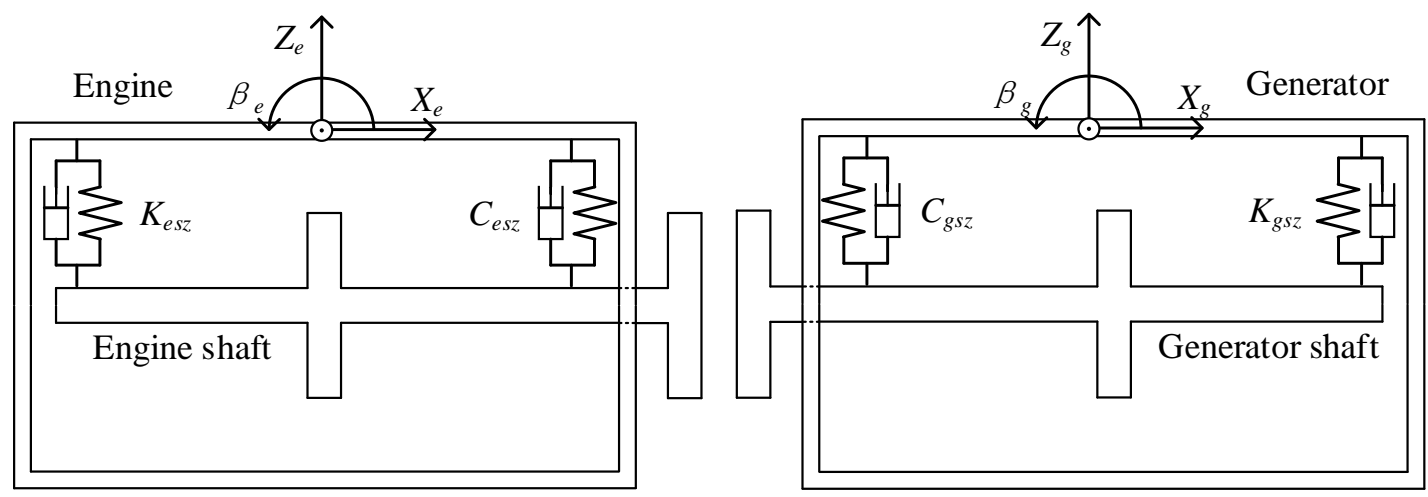


(a) Front view

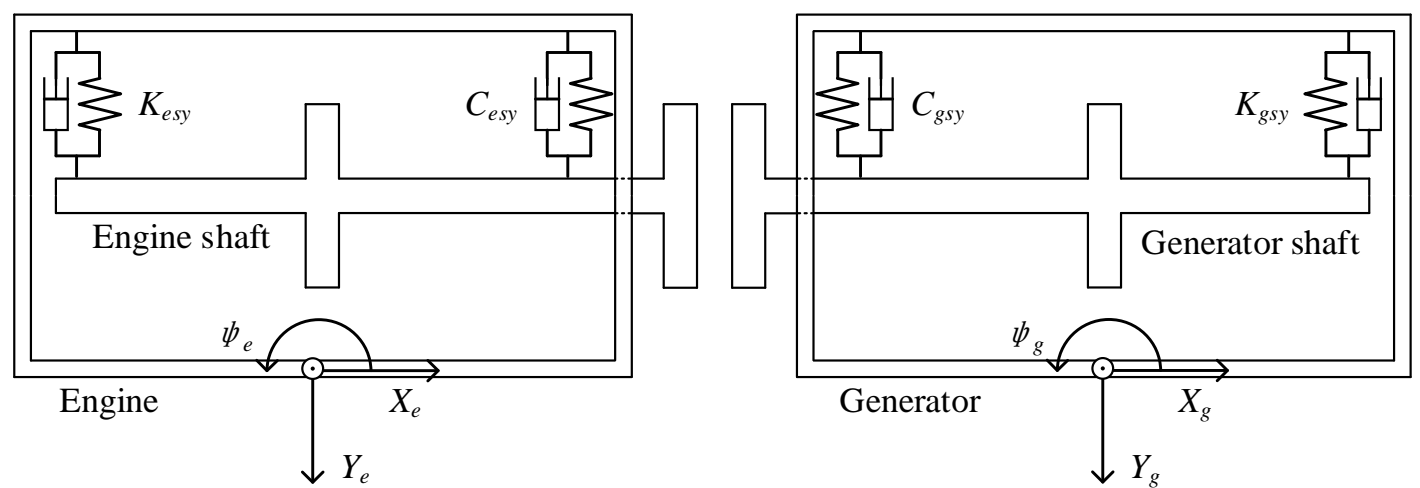

(b) Top view

Engine/Generator

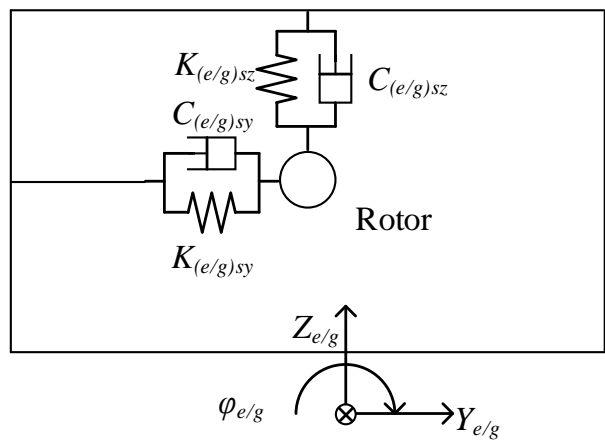

(c) Back view

Fig.3 Schematics of the rotors and engine/generator

First stage isolators, second stage isolators and engine/generator rotor supports operate as linear spring and viscous damper pairs. For simplicity, the engine and generator, and the rotors inside them are identical respectively; gravity centers of the engine and generator are in the axis of symmetry of the public framework in Fig.2b and Fig.2c, and they are coincident with gravity centers of the rotors when stationary and perfectly aligned.

\subsection{Mathematical Model}

\subsubsection{Isolator and rotor support forces}

The first stage isolator forces between the engine/generator and public framework, the second stage isolator forces between the public framework and car body, and rotor support forces between rotor and engine/generator, are calculated based on the generalized relative displacement and velocity of connected components. Note that those forces are positive in compression.

(1) The first stage isolator forces

$$
\begin{aligned}
F_{f y(L, R) i}= & K_{f i y}\left[ \pm Y_{p f} \mp Y_{e / g} \mp l_{1} \varphi_{p f} \mp l_{2, e l g} \varphi_{e l g} \mp(-1)^{j} l_{3, i} \psi_{p f} \pm(-1)^{i} l_{4, e l g} \psi_{e / g}\right] \\
& +C_{f i y}\left[ \pm \dot{Y}_{p f} \mp \dot{Y}_{e / g} \mp l_{1} \dot{\varphi}_{p f} \mp l_{2, e l g} \dot{\varphi}_{e l g} \mp(-1)^{j} l_{3, i} \dot{\psi}_{p f} \pm(-1)^{i} l_{4, e / g} \dot{\psi}_{e / g}\right] \\
F_{f i z(L, R) i} & =K_{f i z}\left[Z_{e / g}-Z_{p f} \mp l_{5} \varphi_{p f} \pm l_{6, e l g} \varphi_{e / g}-(-1)^{\mathrm{j}} l_{7, i} \beta_{p f}+(-1)^{i} l_{8, e l g} \beta_{e / g}\right] \\
& +C_{f i z}\left[\dot{Z}_{e / g}-\dot{Z}_{p f} \mp l_{5} \dot{\varphi}_{p f} \pm l_{6, e l g} \dot{\varphi}_{e / g}-(-1)^{j} l_{7, i} \dot{\beta}_{p f}+(-1)^{i} l_{8, e l g} \dot{\beta}_{e / g}\right]
\end{aligned}
$$


In Equations (1) and (2), $F_{f i y L i}$ and $F_{f i z L i}$ are the horizontal and vertical forces of the $i$-th left first stage isolator force, respectively; $F_{f i y R i}$ and $F_{f i z R i}$ are the horizontal and vertical forces of the $i$-th right first stage isolator force, respectively. In those equations: subscript $L$ denotes the isolators on the left side in the car's moving direction, namely the four first stage isolators on the upper side of Fig.2b; while subscript $R$ denotes the right side; $i$ will be 1,2, 3 or 4, and refers to the first stage isolators in $Y$ and $Z$ direction from left to right in Fig.2b and Fig.2a respectively; $j$ is 1, when $i$ is 1 or 2, and 2 when $i$ is 3 or 4 ; the subscript $e / g$ denotes the generalized displacement or velocity of engine or generator, in this case, $e / g$ is $e$ when $i$ is 1 or 2 , and $g$ when $i$ is 3 or 4; if the subscript of the left equation is $L$, the symbols \pm and $\mp$ take the above one; and if the subscript of the left equation is $R$, the symbols take the below one; the symbol $l$ with different subscripts are illustrated in Appendix A; the stiffness and damping of isolators and rotor supports are listed in Table 1.

Table 1 Structural parameters of isolators and rotor supports

\begin{tabular}{ccc}
\hline Parameter & Physical meaning & Value \\
$K_{f i y}(\mathrm{~N} / \mathrm{mm})$ & Stiffness of first stage isolator in horizontal direction & 500 \\
$C_{f i y}(\mathrm{~N} \cdot \mathrm{s} / \mathrm{mm})$ & Damping of first stage isolator in horizontal direction & 30 \\
$K_{f i z}(\mathrm{~N} / \mathrm{mm})$ & Stiffness of first stage isolator in vertical direction & 500 \\
$C_{f i z}(\mathrm{~N} \cdot \mathrm{s} / \mathrm{mm})$ & Damping of first stage isolator in vertical direction & 30 \\
$K_{s i y}(\mathrm{~N} / \mathrm{mm})$ & Stiffness of second stage isolator in horizontal direction & 500 \\
$C_{s i y}(\mathrm{~N} \cdot \mathrm{s} / \mathrm{mm})$ & Damping of second stage isolator in horizontal direction & 30 \\
$K_{s i z}(\mathrm{~N} / \mathrm{mm})$ & Stiffness of second stage isolator in vertical direction & 500 \\
$C_{s i z}(\mathrm{~N} \cdot \mathrm{s} / \mathrm{mm})$ & Damping of second stage isolator in vertical direction & 30 \\
$K_{e s y}(\mathrm{~N} / \mathrm{mm})$ & Stiffness of engine rotor support in horizontal direction & 1000 \\
$C_{e s y}(\mathrm{~N} \cdot \mathrm{s} / \mathrm{mm})$ & Damping of engine rotor support in horizontal direction & 50 \\
$K_{e s z}(\mathrm{~N} / \mathrm{mm})$ & Stiffness of engine rotor support in vertical direction & 1000 \\
$C_{e s z}(\mathrm{~N} \cdot \mathrm{s} / \mathrm{mm})$ & Damping of engine rotor support in vertical direction & 50 \\
$K_{g s y}(\mathrm{~N} / \mathrm{mm})$ & Stiffness of generator rotor support in horizontal direction & 1000 \\
$C_{g s y}(\mathrm{~N} \cdot \mathrm{s} / \mathrm{mm})$ & Damping of generator rotor support in horizontal direction & 50 \\
$K_{g s z}(\mathrm{~N} / \mathrm{mm})$ & Stiffness of generator rotor support in vertical direction & 1000 \\
$C_{g s z}(\mathrm{~N} \cdot \mathrm{s} / \mathrm{mm})$ & Damping of generator rotor support in vertical direction & 50 \\
\hline
\end{tabular}

(2) The second stage isolator forces

$$
\begin{aligned}
F_{s i y(L, R) k} & =K_{s i y}\left[ \pm Y_{c} \mp Y_{p f} \mp l_{9} \varphi_{c} \mp l_{10} \varphi_{p f} \mp(-1)^{k} l_{11} \psi_{c} \pm(-1)^{k} l_{12} \psi_{p f}\right] \\
& +C_{s i y}\left[ \pm \dot{Y}_{c} \mp \dot{Y}_{p f} \mp l_{9} \dot{\varphi}_{c} \mp l_{10} \dot{\varphi}_{p f} \mp(-1)^{k} l_{11} \dot{\psi}_{c} \pm(-1)^{k} l_{12} \dot{\psi}_{p f}\right] \\
F_{s i z(L, R) k} & =K_{s i z}\left[Z_{p f}-Z_{c} \mp l_{13} \varphi_{c} \pm l_{14} \varphi_{p f}-(-1)^{k} l_{15} \beta_{c}+(-1)^{k} l_{16} \beta_{p f}\right] \\
& +C_{s i z}\left[\dot{Z}_{p f}-\dot{Z}_{c} \mp l_{13} \dot{\varphi}_{c} \pm l_{14} \dot{\varphi}_{p f}-(-1)^{k} l_{15} \dot{\beta}_{c}+(-1)^{k} l_{16} \dot{\beta}_{p f}\right]
\end{aligned}
$$


In Equations (3) and (4), $F_{\text {siyLk }}$ and $F_{\text {sizLk }}$ are the horizontal and vertical forces of the $k$-th left second stage isolator force, respectively; $F_{\text {siyRk }}$ and $F_{\text {sizRk }}$ are the horizontal and vertical forces of the $k$-th right second stage isolator force, respectively. And $k$ will be 1 or 2 , and refers to the second stage isolators in $Y$ and $Z$ direction from left to right in Fig.2b and Fig.2a respectively.

(3) The engine rotor support forces

$$
\begin{aligned}
F_{e s y m}= & K_{e s y}\left[Y_{e}-Y_{e m}-(-1)^{m} l_{17} \psi_{e}\right] \\
& +C_{e s y}\left[\dot{Y}_{e}-\dot{Y}_{e m}-(-1)^{m} l_{17} \dot{\psi}_{e}\right] \\
F_{e s z \mathrm{~m}}= & K_{e s z}\left[Z_{e m}-Z_{e}-(-1)^{m} l_{18} \beta_{e}\right] \\
& +C_{e s z}\left[\dot{Z}_{e m}-\dot{Z}_{e}-(-1)^{m} l_{18} \dot{\beta}_{e}\right]
\end{aligned}
$$

In Equations (5) and (6), $F_{\text {esym }}$ and $F_{\text {eszm }}$ is the horizontal and vertical forces of the $m$-th engine rotor support force, respectively. And $m$ will be 1 or 2, and refers to the engine rotor support in $Y$ and $Z$ direction from left to right in Fig.3b and Fig.3a respectively. The symbols with subscript $\mathrm{em}$ are the generalized displacement and velocity of engine rotor at its supported nodes.

(4) The generator rotor support forces

$$
\begin{aligned}
F_{g s y n}= & K_{g s y}\left[Y_{g}-Y_{g n}-(-1)^{n} l_{19} \psi_{g}\right] \\
& +C_{g s x}\left[\dot{Y}_{g}-\dot{Y}_{g n}-(-1)^{n} l_{19} \dot{\psi}_{g}\right] \\
F_{g s z \mathrm{n}}= & K_{g s z}\left[Z_{g n}-Z_{g}-(-1)^{n} l_{20} \beta_{g}\right] \\
& +C_{g s z}\left[\dot{Z}_{g n}-\dot{Z}_{g}-(-1)^{n} l_{20} \dot{\beta}_{g}\right]
\end{aligned}
$$

In Equations (7) and (8), $F_{g s y n}$ and $F_{g s z n}$ is the horizontal and vertical forces of the $n$-th generator rotor support force, respectively. And $n$ will be 1 or 2, and refers to the generator rotor support in $Y$ and $Z$ direction from left to right in Fig.3b and Fig.3a respectively. The symbols with subscript $g n$ are the generalized displacement and velocity of generator rotor at its supported nodes.

\subsubsection{Equations of motion of the powerpack}

Equations of motion of the components of the powerpack dynamic system are established according to the D'Alembert's Principle.

(1) The equations of motion of the public framework

The public framework is connected with car body through first stage isolators, and with engine and generator through second stage isolators, thus, equations are followed as:

Lateral motion:

$$
M_{p f} \ddot{Y}_{p f}+\sum_{i=1}^{4}\left(F_{f i y L i}-F_{f y X i}\right)-\sum_{k=1}^{2}\left(F_{s i y L k}-F_{s i y R k}\right)=0
$$

Bounce motion:

$$
M_{p f} \ddot{Z}_{p f}-\sum_{i=1}^{4}\left(F_{f i z L i}+F_{f i z R i}\right)+\sum_{k=1}^{2}\left(F_{s i z L k}+F_{s i z R k}\right)=0
$$

Roll motion: 


$$
J_{p f i} \ddot{\varphi}_{p f}-\sum_{i=1}^{4}\left(F_{f i y L i}-F_{f i y R i}\right) l_{1}-\sum_{i=1}^{4}\left(F_{f i z L i}-F_{f i z R i}\right) l_{5}-\sum_{k=1}^{2}\left(F_{s i y L k}-F_{s i y R k}\right) l_{10}+\sum_{k=1}^{2}\left(F_{s i z L k}-F_{s i z R k}\right) l_{14}=0
$$

Pitch motion:

$$
J_{p f y} \ddot{\beta}_{p f}-\sum_{i=1}^{4}(-1)^{j}\left(F_{f i z L i}+F_{f i z R i}\right) l_{7, i}+\sum_{k=1}^{2}(-1)^{k}\left(F_{s i z L k}+F_{s i z R k}\right) l_{16}=0
$$

Yaw motion:

$$
J_{p f z} \ddot{\psi}_{p f}-\sum_{i=1}^{4}(-1)^{j}\left(F_{f i y L i}-F_{f y Y R i}\right) l_{3, i}+\sum_{k=1}^{2}(-1)^{k}\left(F_{s i y L k}-F_{s i y R k}\right) l_{12}=0
$$

In Equations (9)-(13), $M_{p f}, J_{p f x}, J_{p f y}$ and $J_{p f z}$ are listed in Table 2.

(2) The equations of motion of the engine

The engine is hung to the public framework through the first stage isolators, and under excitations from the engine rotor supports inside the engine.

Lateral motion:

$$
M_{e} \ddot{Y}_{e}+\sum_{m=1}^{2} F_{e s y m}-\sum_{i=1}^{2}\left(F_{f i y L i}-F_{f i y R i}\right)=0
$$

Bounce motion:

$$
M_{e} \ddot{Z}_{e}-\sum_{m=1}^{2} F_{e s z m}+\sum_{i=1}^{2}\left(F_{f i z L i}+F_{f i z R i}\right)=0
$$

Roll motion:

$$
J_{e x} \ddot{\varphi}_{e}-\sum_{i=1}^{2}\left(F_{f i y L i}-F_{f y R i}\right) l_{2, e}+\sum_{i=1}^{2}\left(F_{f i z L i}-F_{f i z R i}\right) l_{6, e}=0
$$

Pitch motion:

$$
J_{e y} \ddot{\beta}_{e}-\sum_{\mathrm{m}=1}^{2}(-1)^{m} F_{e s z m} l_{18}+\sum_{i=1}^{2}(-1)^{i}\left(F_{f i z L i}+F_{f i z R i}\right) l_{8, e}=0
$$

Yaw motion:

$$
J_{e z} \ddot{\psi}_{e}-\sum_{m=1}^{2}(-1)^{m} F_{e s y m} l_{17}+\sum_{i=1}^{2}(-1)^{i}\left(F_{f i y L i}-F_{f i y R i}\right) l_{4, e}=0
$$

In Equations (14)-(18), $M_{e}, J_{e x}, J_{e y}$ and $J_{e z}$ are listed in Table.2.

(3) The equations of motion of the generator

The generator is hung to the public framework through the first stage isolators, and under excitations from the generator rotor supports inside the generator.

Lateral motion:

$$
M_{g} \ddot{Y}_{g}+\sum_{n=1}^{2} F_{g s y n}-\sum_{i=3}^{4}\left(F_{f i y L i}-F_{f i y R i}\right)=0
$$


Bounce motion:

$$
M_{g} \ddot{Z}_{g}-\sum_{n=1}^{2} F_{g s z n}+\sum_{i=3}^{4}\left(F_{f i Z L i}+F_{f i Z R i}\right)=0
$$

Roll motion:

$$
J_{g x} \ddot{\varphi}_{g}-\sum_{i=3}^{4}\left(F_{f i y L i}-F_{f i y R i}\right) l_{2, g}+\sum_{i=3}^{4}\left(F_{f i z L i}-F_{f i z R i}\right) l_{6, g}=0
$$

Pitch motion:

$$
J_{g y} \ddot{\beta}_{g}-\sum_{n=1}^{2}(-1)^{n} F_{g s z n} l_{20}+\sum_{i=3}^{4}(-1)^{i}\left(F_{f i z L i}+F_{f i z R i}\right) l_{8, g}=0
$$

Yaw motion:

$$
J_{g z} \ddot{\psi}_{g}-\sum_{n=1}^{2}(-1)^{n} F_{g s y n} l_{19}+\sum_{i=3}^{4}(-1)^{i}\left(F_{f y L L}-F_{f y x R}\right) l_{4, g}=0
$$

\begin{tabular}{|c|c|c|}
\hline Parameter & Physical meaning & Value \\
\hline$M_{p f}(\mathrm{~kg})$ & Mass of the public framework & 181.67 \\
\hline$J_{p f x}\left(\mathrm{~kg} \cdot \mathrm{mm}^{2}\right)$ & Moment of inertia of the public framework around $X$ & $2.4 \times 10^{9}$ \\
\hline$J_{p f y}\left(\mathrm{~kg} \cdot \mathrm{mm}^{2}\right)$ & Moment of inertia of the public framework around $Y$ & $1.1 \times 10^{9}$ \\
\hline$J_{p f z}\left(\mathrm{~kg} \cdot \mathrm{mm}^{2}\right)$ & Moment of inertia of the public framework around $Z$ & $1.3 \times 10^{8}$ \\
\hline$M_{e}(\mathrm{~kg})$ & Mass of the engine & 1344 \\
\hline$J_{e x}\left(\mathrm{~kg} \cdot \mathrm{mm}^{2}\right)$ & Moment of inertia of the engine around $X$ & $2.3 \times 10^{8}$ \\
\hline$J_{e y}\left(\mathrm{~kg} \cdot \mathrm{mm}^{2}\right)$ & Moment of inertia of the engine around $Y$ & $2.9 \times 10^{8}$ \\
\hline$J_{e z}\left(\mathrm{~kg} \cdot \mathrm{mm}^{2}\right)$ & Moment of inertia of the engine around $Z$ & $3.8 \times 10^{8}$ \\
\hline$M_{g}(\mathrm{~kg})$ & Mass of the generator & 1344 \\
\hline$J_{g x}\left(\mathrm{~kg} \cdot \mathrm{mm}^{2}\right)$ & Moment of inertia of the generator around $X$ & $2.3 \times 10^{8}$ \\
\hline$J_{g y}\left(\mathrm{~kg} \cdot \mathrm{mm}^{2}\right)$ & Moment of inertia of the generator around $Y$ & $2.9 \times 10^{8}$ \\
\hline$J_{g z}\left(\mathrm{~kg} \cdot \mathrm{mm}^{2}\right)$ & Moment of inertia of the generator around $Z$ & $3.8 \times 10^{8}$ \\
\hline
\end{tabular}

In Equations (19)-(23), $M_{g}, J_{g x}, J_{g y}$ and $J_{g z}$ are listed in Table 2.

Table 2 Structural parameters of the rigid bodies in the powerpack

Simplification of Equations (9)-(23) can form a differential matrix of the second order as

$$
M \ddot{Q}+C \dot{Q}+K Q=F,
$$

symbols in which are further illustrated in Appendix B.

\subsubsection{Equations of motion of the rotors}

The rotors of the engine and generator are modelled based on Finite Element Method, as shown in Fig.4. 
The parameters of both rotors are identical for simplicity, as listed in Table 3.

For the engine (Fig.4a), the crankshaft is simplified as a hollow shaft with two disks of equal size, with the lumped mass of all cranks at Node 5 and the flywheel at Node 13. And the engine rotor supports locate at Node 1 and 9, the generalized displacement and velocity of which are $Y_{e m}, Z_{e m}, \dot{Y}_{e m}$ and $\dot{Z}_{e m}$ in Equations (5) and (6) respectively.

For the generator (Fig.4b), the rotor is similar to the engine rotor, and the disk at Node 1 represents the elastic coupling and the disk at Node 9 represents the lumped mass of the armatures. The generator rotor supports locate at Node 5 and 13, the generalized displacement and velocity of which are $Y_{g n}, Z_{g n}, \dot{Y}_{g n}$ and $\dot{Z}_{g n}$ in Equations (7) and (8) respectively.

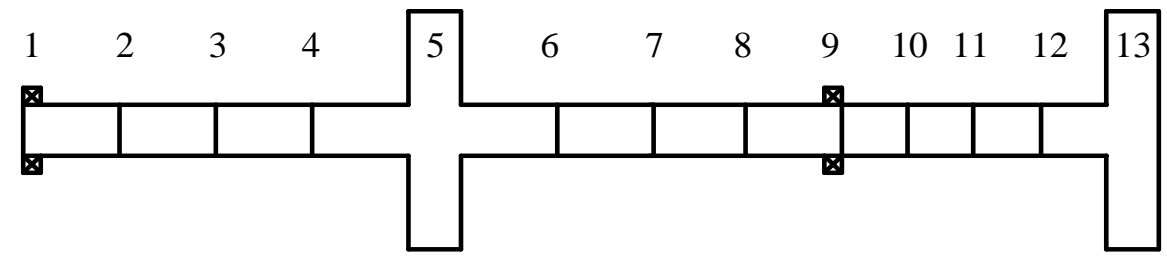

(a) Rotor of engine

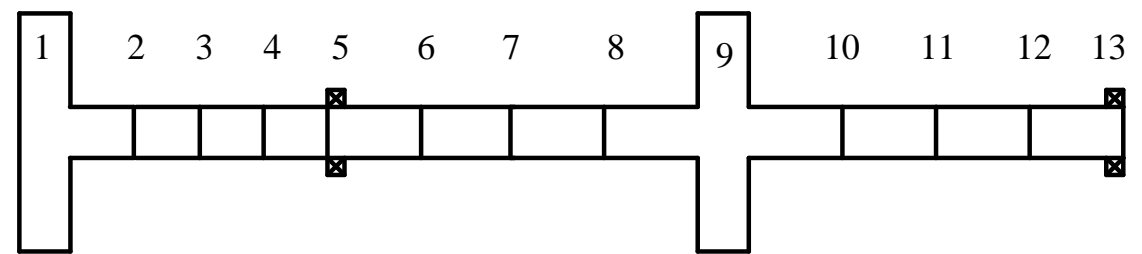

(b) Rotor of generator

Fig.4 Schematics of the rotors

Table 3 Structural parameters of FE Model

\begin{tabular}{ccc}
\hline Parameter & Physical meaning & Value \\
$\rho\left(\mathrm{kg} / \mathrm{m}^{3}\right)$ & Density of the shaft & 7850 \\
$u$ & Poisson's ratio of the shaft & 0.3 \\
$r_{\text {inner }}(\mathrm{mm})$ & Inner radius of shaft & 10 \\
$r_{\text {outer }}(\mathrm{mm})$ & Outer radius of shaft & 25 \\
$l 1_{\text {nodes }}(\mathrm{mm})$ & Axial distance between adjacent nodes & 150 \\
& (For Nodes $1-9$ in Fig.3a and & \\
$l 2_{\text {nodes }}(\mathrm{mm})$ & Nodes $5-13$ in Fig.3b) & 50 \\
& Axial distance between adjacent nodes & \\
$m_{\text {disk }}(\mathrm{kg})$ & (For Nodes $9-13$ in Fig.3a and & 35 \\
$J p_{\text {disk }}\left(\mathrm{kg} \cdot \mathrm{mm}{ }^{2}\right)$ & Nodes $1-5$ in Fig.3b) & Mass of disk \\
\hline
\end{tabular}




$$
J d_{d i s k}\left(\mathrm{~kg} \cdot \mathrm{mm}^{2}\right) \quad \text { Diameter moment of inertia of disk }
$$

$4.166 \times 10^{5}$

Equations of motion of rotors are followed as

$$
M_{r-e / g} \ddot{q}_{e / g}+C_{r-e / g} \dot{q}_{e / g}-2 \pi f G_{r-e / g} \dot{q}_{e / g}+K_{r-e / g} q_{e / g}=F_{r-e / g} .
$$

$M_{r-e / g}, C_{r-e / g}, G_{r-e / g}$ and $K_{r-e / g}$ are the mass, damping, gyroscopic and stiffness matrices of the rotors respectively, and were obtained based on [19]. $f$ is the rotating frequency, and rotors of engine and generator are distinguished by subscripts $e / g$. Vibrations of rotors appear in $y, z, \theta y$ and $\theta z$ direction, which are the same directions as $Y, Z, \beta$ and $\psi$ in Fig.2 respectively. As for the powerpack motion, the longitudinal vibration in the $x$ axis is negligible and is not considered here. $q_{e / g}=\left(y_{1 e / g}, \theta y_{1 e / g}, \ldots, \theta y_{13 e / g}, z_{1 e / g}, \ldots, \theta z_{13 e / g}\right)^{T}$ and $q_{e / g}$ is the generalized displacement of rotor. $F_{r-e / g}$ is the external excitation of the rotor. For the following simulation, rotors are under excitations from elastic rotor support, mass unbalance (locates at Node 13 in Fig.4a and Node 1 in Fig.4b) and DSM. The method to calculate DSM is introduced in previous work.

\section{Numerical Simulation}

Equations (24) and (25) are numerically evaluated using the Newmark method, and the procedure is shown in Fig.5. At time step $t$, there are the generalized displacement and velocity of engine and generator, rotors, and car body. From the former two terms, forces of rotor supports can be obtained, which form the external excitation of rotors together with mass unbalance and DSM. In other words, $F_{r-e}$ and $F_{r-g}$ are obtained. From the latter two terms, the external excitation of the powerpack, namely $F$ is obtained. With $F_{r-e / g}$ and $F$ known, the dynamic responses of the rotors and the powerpack can be simulated. To start the simulation, the initial generalized displacement and velocity of rotors and the powerpack are zero, and base motions of car body are applied according to former research[4]. 


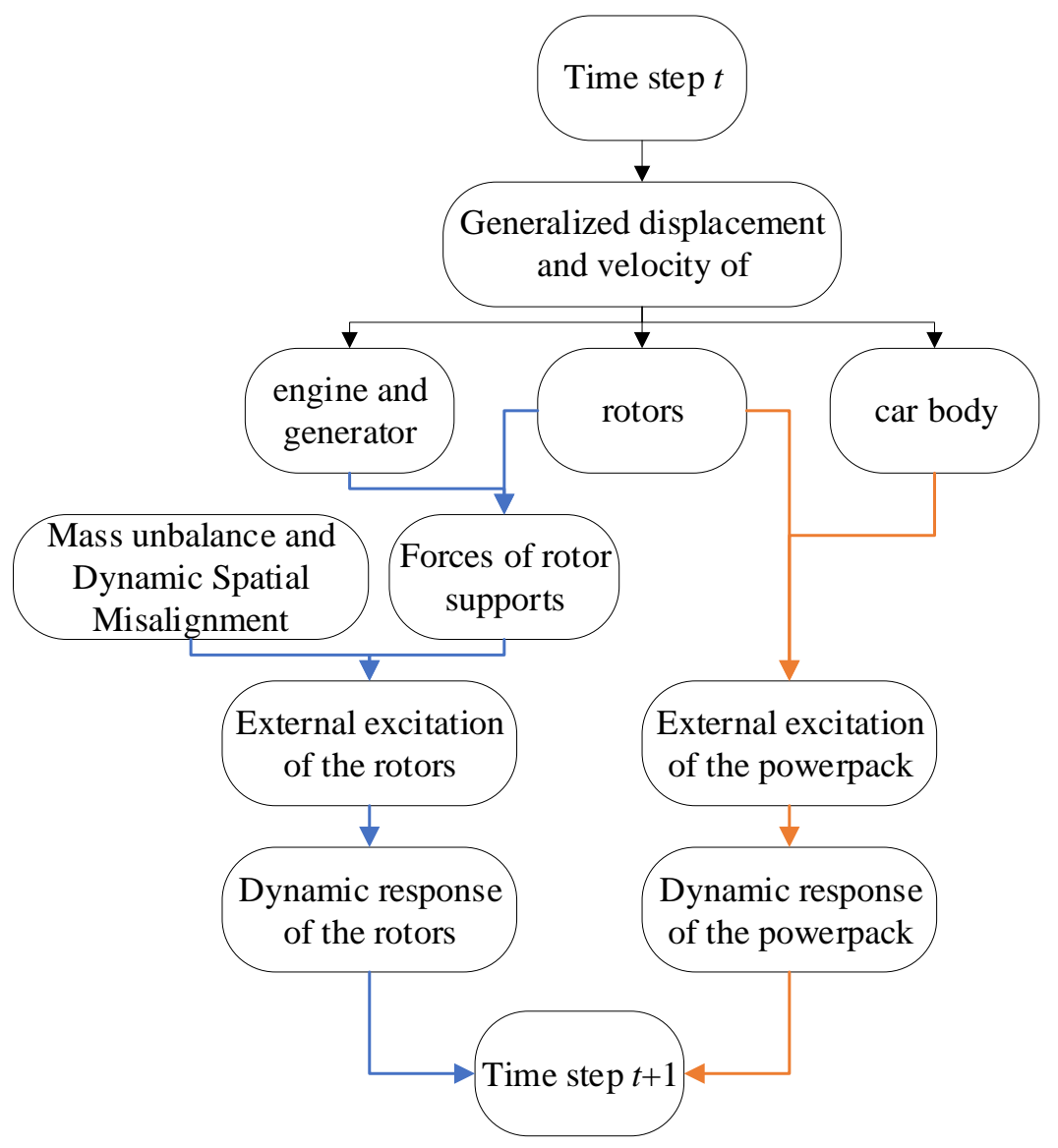

Fig.5 Simulation procedure

In this chapter, the rotors rotate at a stable frequency of $30 \mathrm{~Hz}$, and there is a phase difference of $\pi \mathrm{rad}$ between the same-amplitude eccentric forces of engine and generator rotors. The eccentric force $f_{e}=m_{e} e_{e}(2 \pi f)^{2}$, and $m_{e} e_{e}$ is $25 \mathrm{~kg} \cdot \mathrm{mm}$. The elastic coupling is $90 \mathrm{~mm}$ in width, and axially divided into 30 pieces. The initial misalignment is a parallel one in the plane $O_{I} Y_{I} Z_{I}$ and the amplitude is $1 \mathrm{~mm}$ reference previous work.

As for the base motions, the generalized displacement of car body in one direction is $A_{b} \sin \left(2 \pi f_{b}\right)$, where $A_{b}$ is the amplitude and $f_{b}$ is the frequency. So, the generalized velocity is $2 \pi A_{b} f_{b} \cos \left(2 \pi f_{b}\right)$.

The total simulation time is 15 seconds, and the time step is $0.0001 \mathrm{~s}$. The frequency component of $f$ in response, or the synchronous whirl, is defined as $1 \times$. Components in response with frequency multiples of $f$ are defined as $2 \times, 3 \times$, etc.

\subsection{Deterministic Base Motion}

In this section, the frequency of the base motion $f_{b}$ is deterministic and $f_{b}=12 \mathrm{~Hz}$.

\subsubsection{No base motion}

When the amplitude of the base motion from the car body $A_{b}$ is zero, namely no base motion, the dynamic responses of rotors in stable state are shown in Fig.6 - Fig.8.

Despite no base motion, the dynamic rotor responses are still different from those in previous work. The orbits of two rotors are no longer centrosymmetric, and the spectra of horizontal and vertical vibrations remains similar. As for DSM, it is nearly identical along the coupling in spectra in Fig.8a, but not in time waveform, which means the centerlines of sleeve and hub are not parallel all the time during rotation any 
more. $p$ is an integer between 1 and 30, which refers to the coupling slice in different axial position. Time waveform of $p$-th coupling slice, highlighted by the red box in Fig.8a, is shown in Fig.8b.

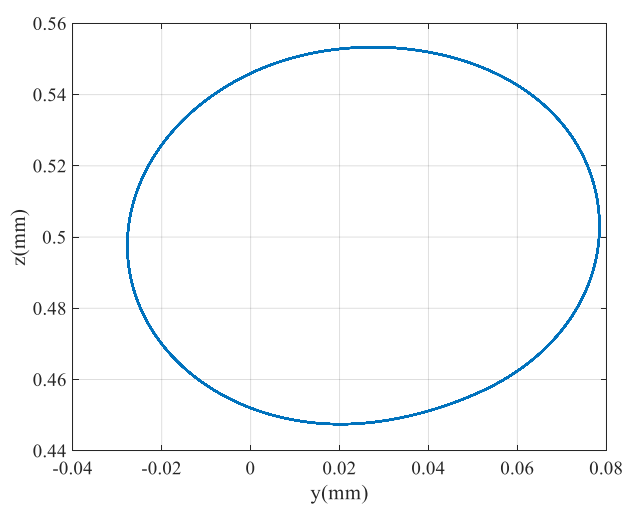

(a)

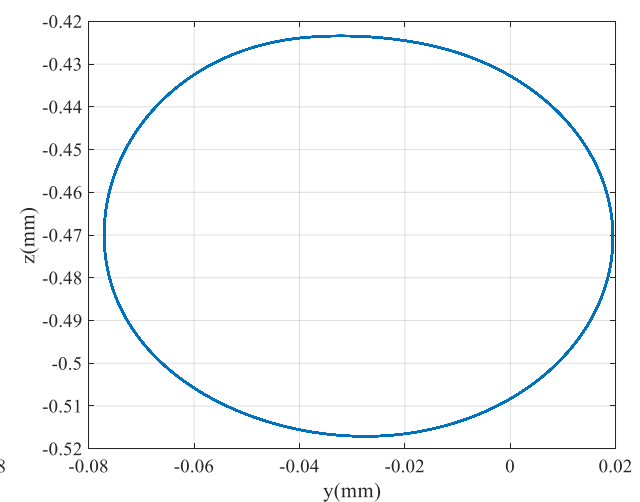

(b)

Fig.6 Orbits of (a) engine rotor and (b) generator rotor

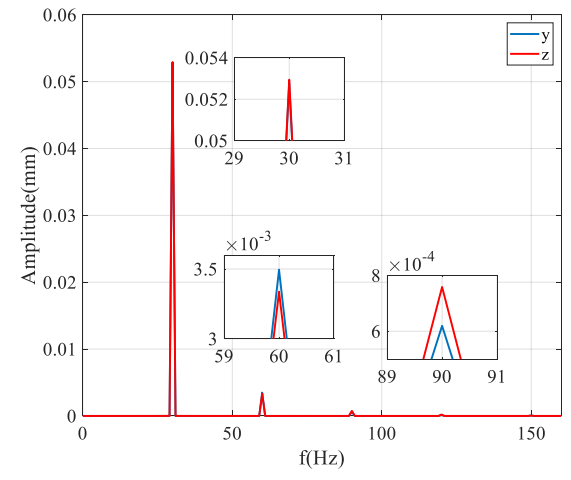

(a)

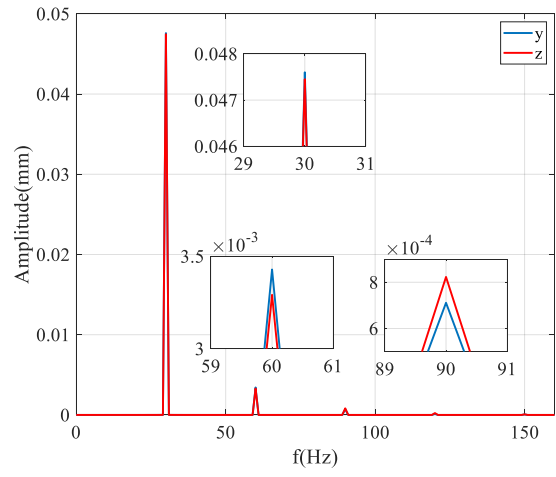

(b)

Fig.7 Spectra of horizontal and vertical vibrations of

(a) the node 13 in engine rotor and (b) the node 1 in generator rotor

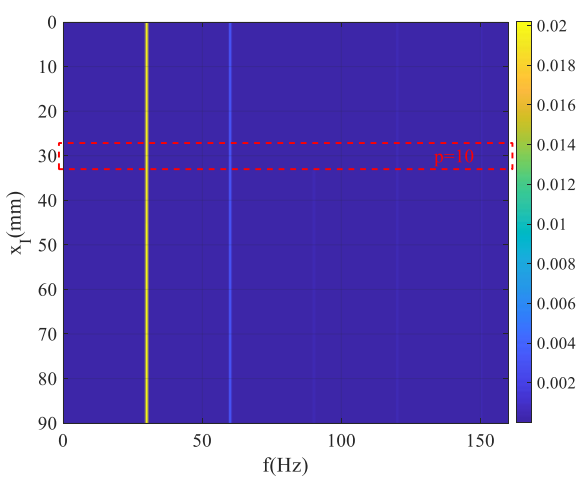

(a)

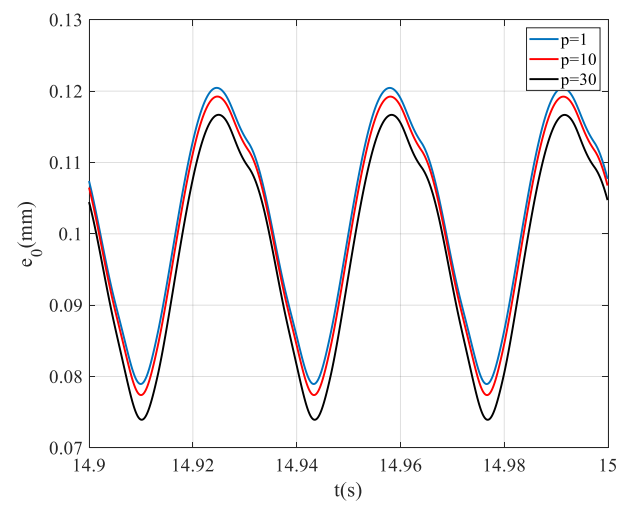

(b)

Fig.8 (a) DSM amplitude versus the frequency along the centerline of the coupling (b) Time waveform of DSM at given position

\subsubsection{Lateral base motion}

Base motion of the car body in the lateral direction is introduced here in section 3.1.2, namely by the 
function $Y_{c}=A_{b} \sin \left(2 \pi f_{b}\right)$.

(1) Amplitude $A_{b}=0.2 \mathrm{~mm}$

In this case, the orbits in Fig. 9 become more complicated. The most prominent frequency component is still $1 \times$, also $2 \times$ and $3 \times$ appear when the amplitude of base motion is small. The frequency component of the base motion, namely $f_{b}$, can be observed in spectra of rotors' horizontal and vertical vibrations, as shown in Fig.10. It appears in both $y$ and $z$ direction due to the centrosymmetric structural characteristic of the elastic coupling, despite that only the lateral base motion of car body is applied. Apparently, the amplitude in the $y$ direction is significantly larger than that in the $z$ direction. Comparison between Fig.8 and Fig.11 shows that DSM is not evidently affected by the lateral base motion in spectra or time waveform in this case.

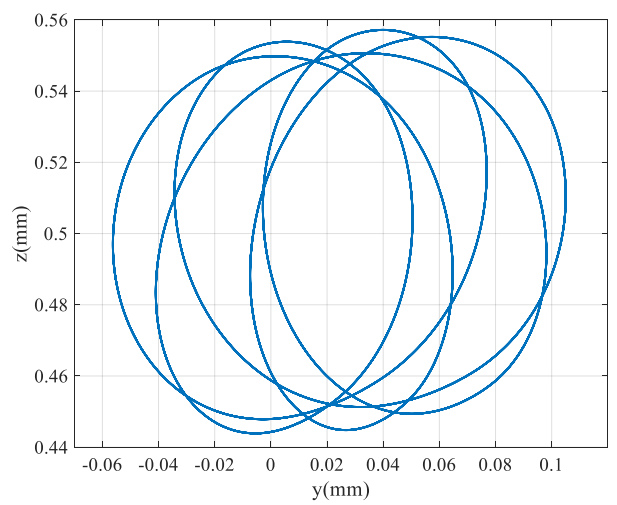

(a)

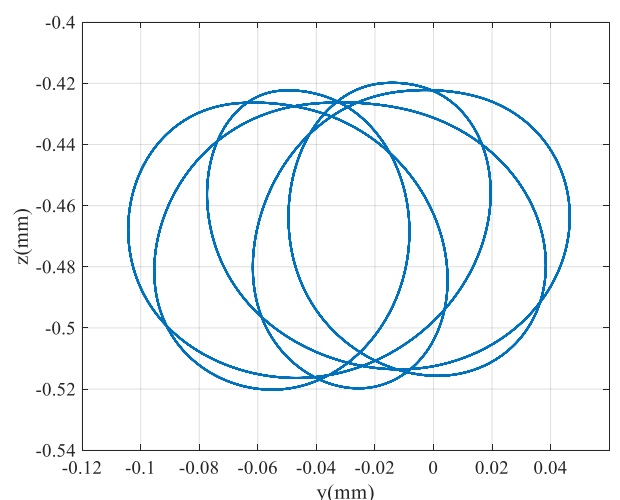

(b)

Fig.9 Orbits of (a) engine rotor and (b) generator rotor

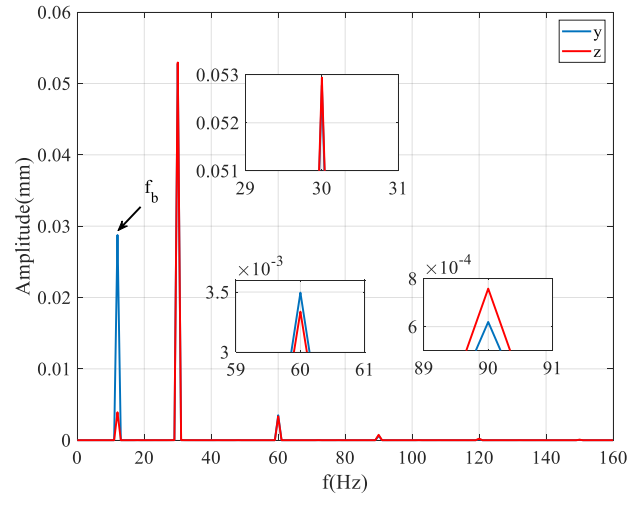

(a)

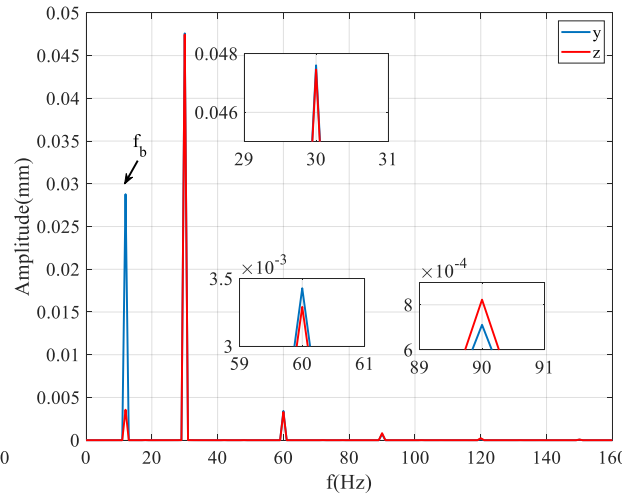

(b)

Fig.10 Spectra of horizontal and vertical vibrations of (a) the node 13 in engine rotor and (b) the node 1 in generator rotor 


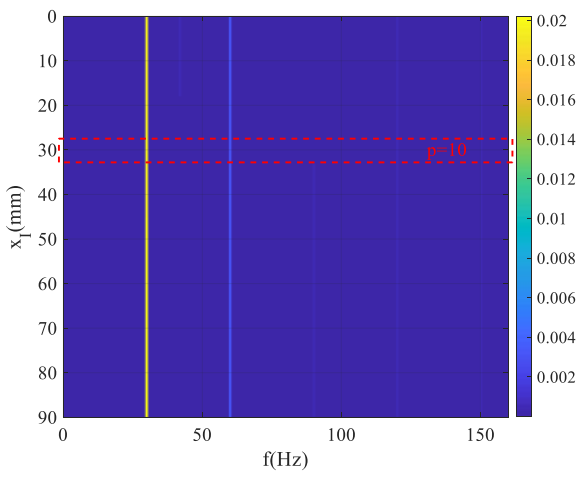

(a)

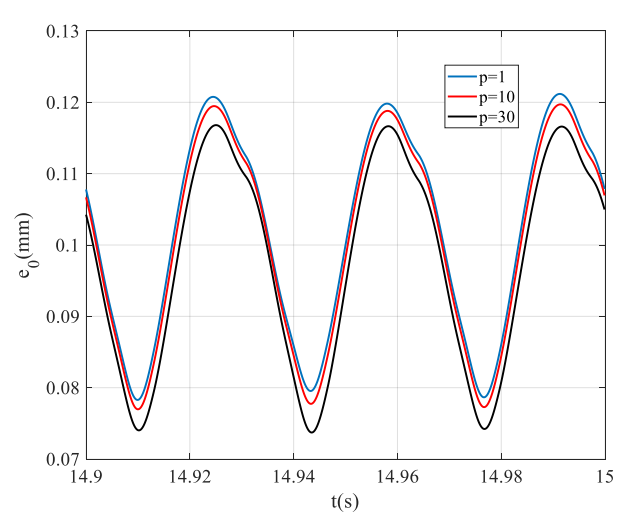

(b)

Fig.11 (a) DSM amplitude versus the frequency along the centerline of the coupling

(b) Time waveform of DSM at given position

\section{(2) Amplitude $A_{b}=1.5 \mathrm{~mm}$}

When the amplitude of the lateral base motion $A_{b}$ reaches $1.5 \mathrm{~mm}$, orbits in Fig.11 are stable but twisty. The major component in spectra (Fig.13) becomes $f_{b}$. The DSM is under modulation effects of the base motion, where $f_{b}, f \pm f_{b}$ can be observed in Fig.14a. The modulation effect here means that DSM and base motion are coupled and affecting each other in time and frequency domain. Considering that no $f_{b}$ appears when $A_{b}=0.2 \mathrm{~mm}$ in the spectra of DSM in Fig. 11a, one can conclude that DSM is more nonlinearly sensitive to the modulation effects of base motion than horizontal and vertical vibrations of rotors in this case, because further calculation shows that spectra of rotors' horizontal and vertical vibrations do not vary in a qualitative way when $A_{b}$ increases from $0.2 \mathrm{~mm}$ to $1.5 \mathrm{~mm}$.

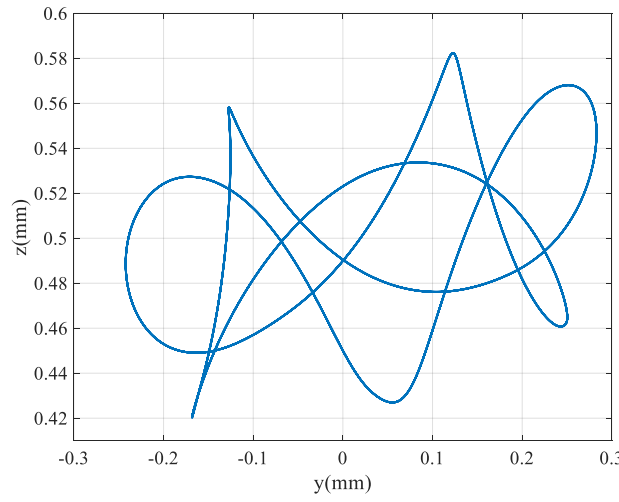

(a)

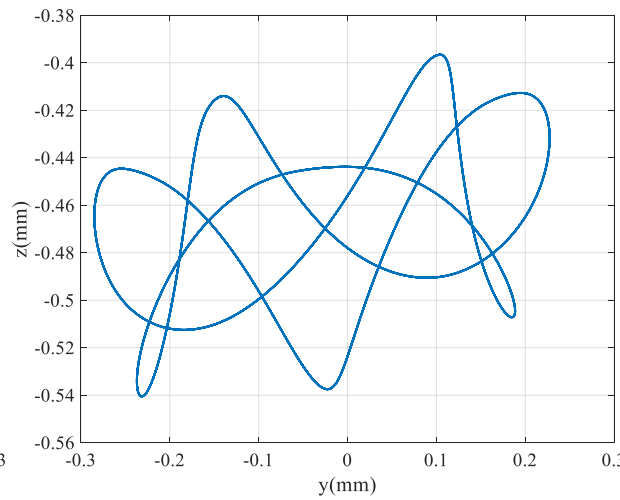

(b)

Fig.12 Orbits of (a) engine rotor and (b) generator rotor
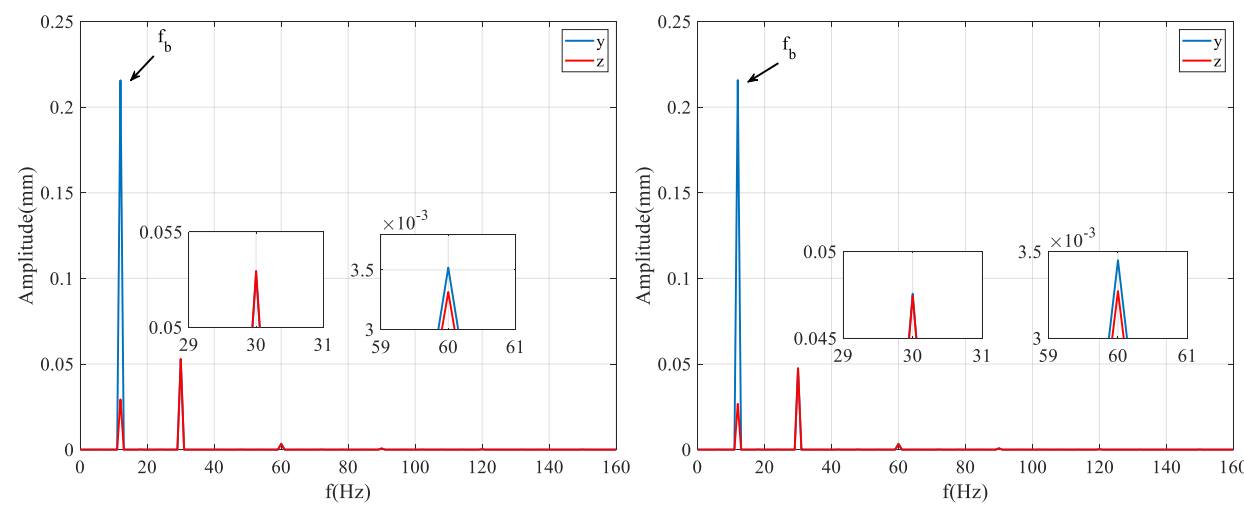
Fig.13 Spectra of horizontal and vertical vibrations of

(a) the node 13 in engine rotor and (b) the node 1 in generator rotor

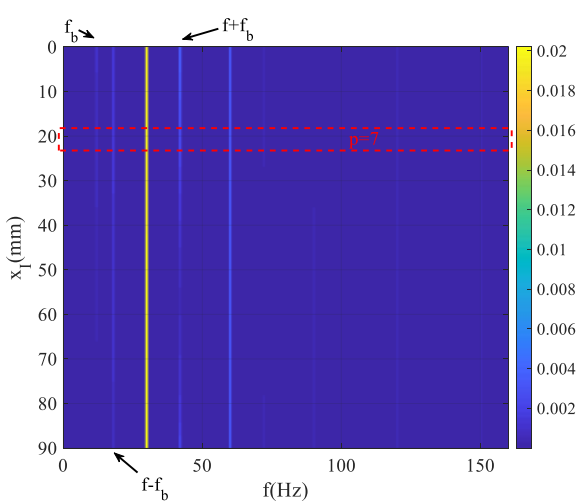

(a)

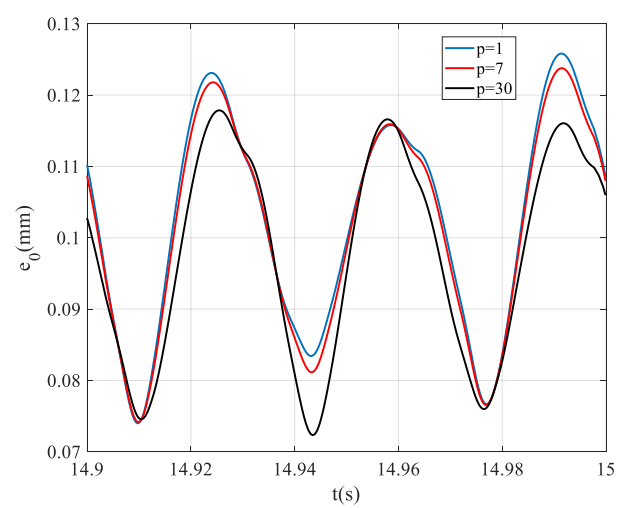

(b)

Fig.14 (a) DSM amplitude versus the frequency along the centerline of the coupling (b) Time waveform of DSM at given position

(3) Amplitude $A_{b}=10 \mathrm{~mm}$

In some extreme situations, the lateral base motion of the car body may reach $10 \mathrm{~mm}$. The stable dynamic responses of engine and generator rotors are shown in Fig. 15 - Fig. 17 for this amplitude base motion.

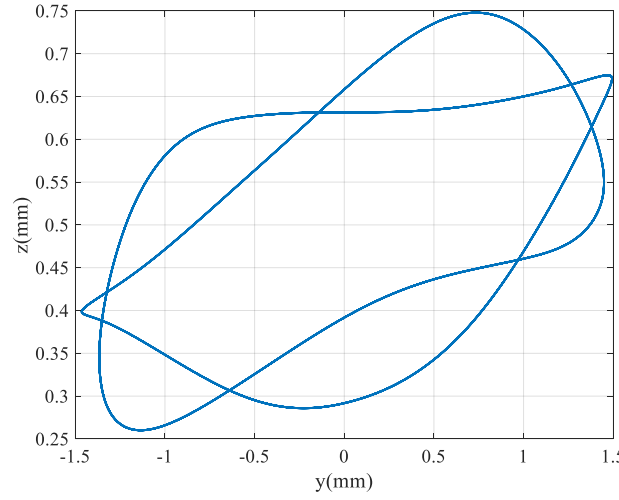

(a)

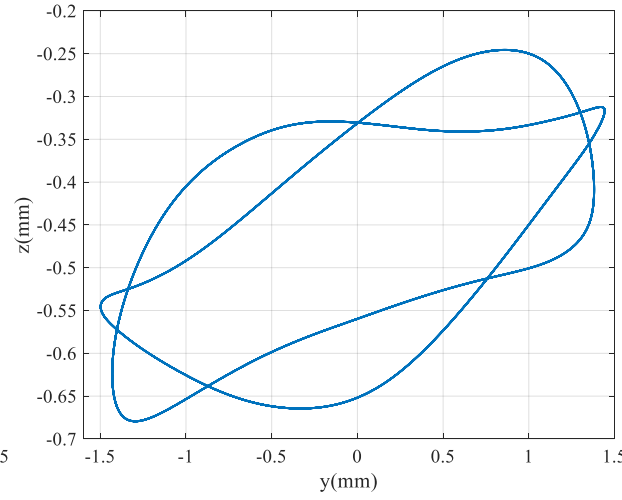

(b)

Fig.15 Orbits of (a) engine rotor and (b) generator rotor

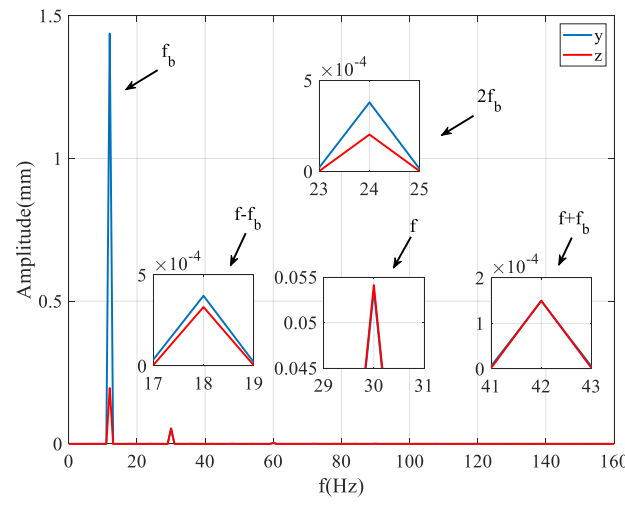

(a)

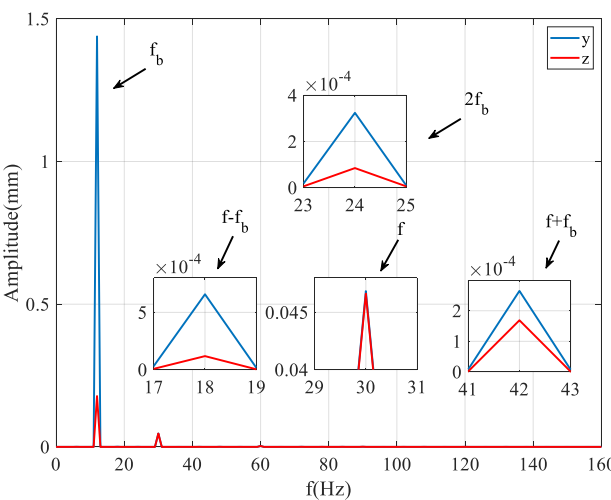

(b) 
Fig.16 Spectra of horizontal and vertical vibrations of

(a) the node 13 in engine rotor and (b) the node 1 in generator rotor

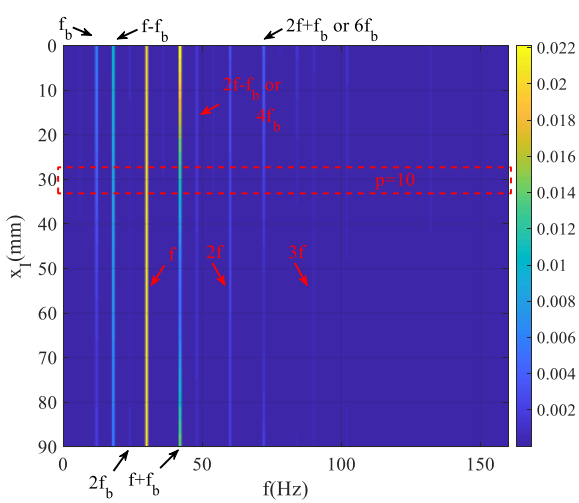

(a)

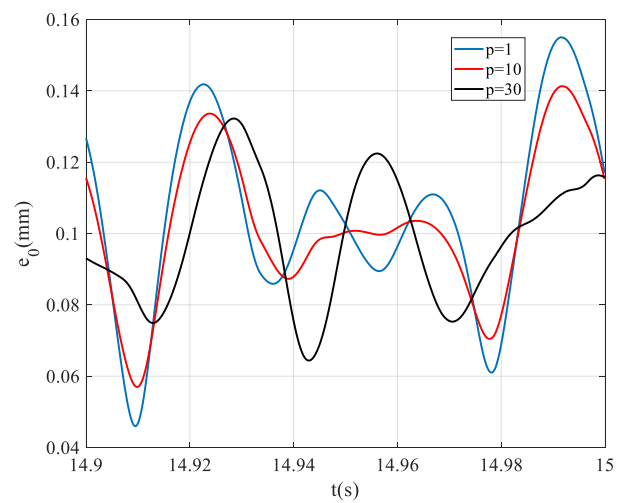

(b)

Fig.17 (a) DSM amplitude versus the frequency along the centerline of the coupling

(b) Time waveform of DSM at given position

Orbits become simple because the lateral base motion is dominant with large $A_{b}$ and constant initial misalignment. Modulation of the base motion on the rotors' vibration can be observed, although amplitudes of frequency components $f \pm f_{b}$ are negligible and at the same magnitude of $3 \times$ in Fig.7 and Fig.10. Spectra of DSM along the centerline of the coupling compose broad frequency components, including $f_{b}, f_{-} f_{b}, 2 f_{b}, f$, $f+f_{b}, 2 f-f_{b}$ or $4 f_{b}, 2 f, 2 f+f_{b}$ or $6 f_{b}$ and $3 f$, etc. Additionally, there are only tiny phase and mean value differences between coupling slices in different axial position when $A_{b}$ is $0.2 \mathrm{~mm}$ and $1.5 \mathrm{~mm}$, as shown in Fig. $11 \mathrm{~b}$ and Fig.14b. But those differences are significant in this case, and the time waveforms of DSM along the centerline of the coupling are no longer the same shape.

\subsubsection{Pitch base motion}

In this section, pitch base motion of the car body appears and $\beta_{c}=A_{b} \sin \left(2 \pi f_{b}\right)$, where $A_{b}=0.0017 \mathrm{rad}$, namely $0.1^{\circ}$. Rotors' vibrations and DSM are shown in Fig. 18 - Fig. 20.

Orbits show the existence of multiple frequency components. As for spectra of the rotors' horizontal and vertical vibrations, frequency components of $f_{b}$ and $1 \times$ remain dominant, while the modulation effects of the base motion are obvious. Vibrations at the frequencies of $f_{b} / 2, f_{-} f_{b}, 2 f_{b}, 3 f_{b}, f+f_{b}, 2 f_{-} f_{b}$ or $4 f_{b}, 2 f$ and $2 f+f_{b}$ or $6 f_{b}$ can be observed in Fig.19. Apart from those components, the spectra of DSM along the centerline of the coupling, in Fig.20a, contain frequencies at $f+2 f_{b}, 3 f_{-} f_{b}$ or $f+4 f_{b}, 2 f+2 f_{b}$ or $7 f_{b}, f+6 f_{b}$ or $3 f+f_{b}$, etc. Note that the pitch base motion is only $0.1^{\circ}$, so modulation effects of this base motion are much more distinct. And the reason is that the pitch base motion of car body at $0.1^{\circ}$ can lead to over $20 \mathrm{~mm}$ displacement at the second stage isolators in $z$ direction. On the other hand, time waveform of DSM in different axial position in Fig.20b shows small variations in phase and mean value. 


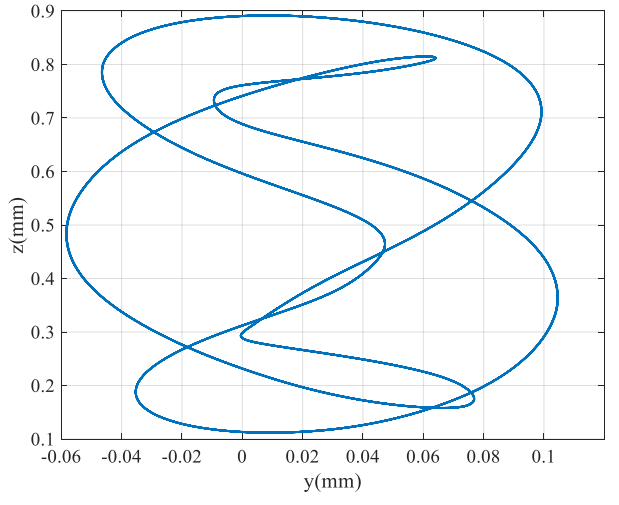

(a)

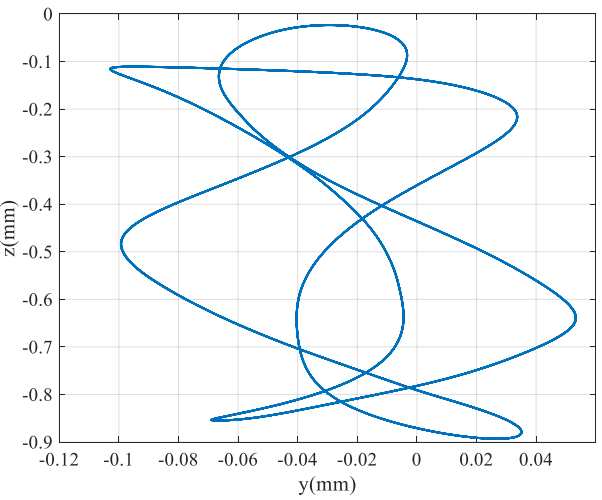

(b)

Fig.18 Orbits of (a) engine rotor and (b) generator rotor

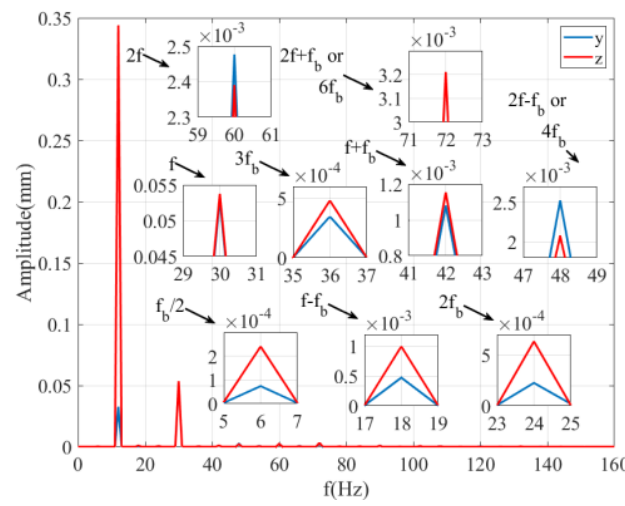

(a)

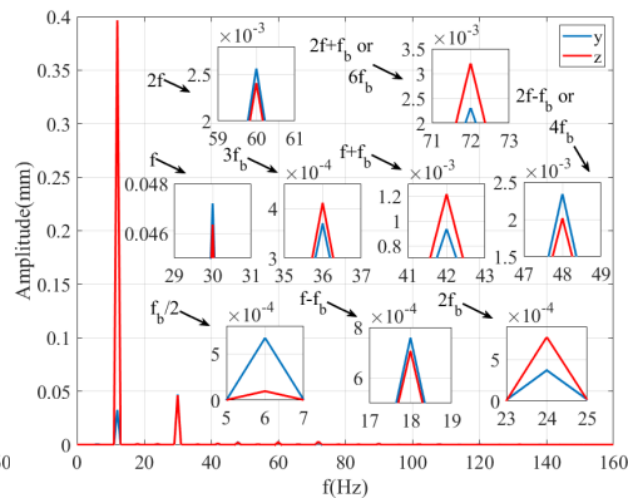

(b)

Fig.19 Spectra of horizontal and vertical vibrations of

(a) the node 13 in engine rotor and (b) the node 1 in generator rotor

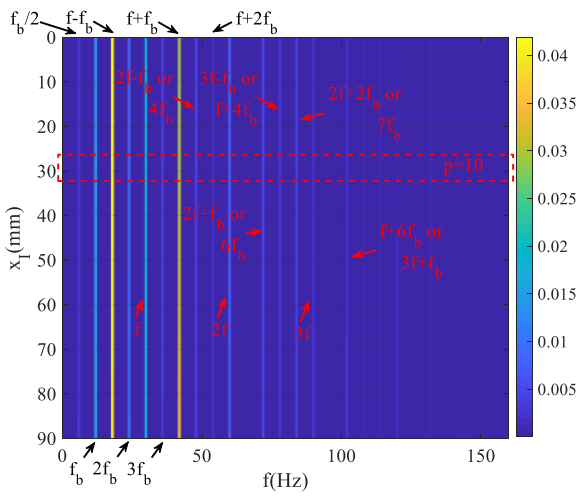

(a)

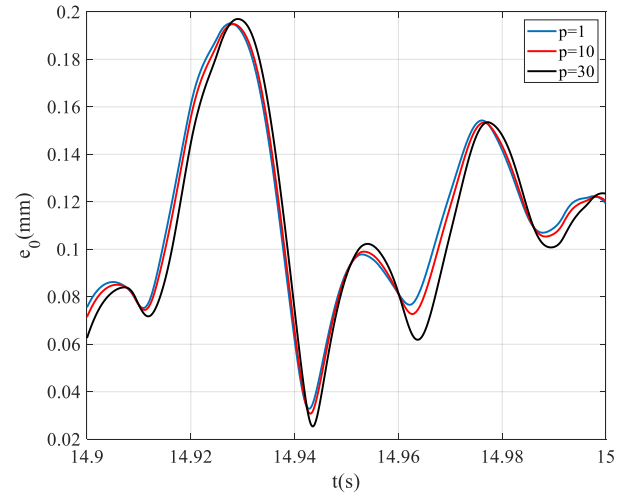

(b)

Fig.20 (a) DSM amplitude versus the frequency along the centerline of the coupling

(b) Time waveform of DSM at given position

Further calculations can conclude that the dynamic responses of rotors with bounce base motion (zdirection) are similar to those with lateral motion. The two cases differ in that the amplitudes of the frequency components in the $z$ direction are larger than those in the $y$ direction (under lateral base motion). Also, pitch, yaw and roll base motion have analogous effects on rotors' vibrations and DSM. 


\subsection{Random Base Motion}

Random pitch base motion is studied in this section. First, a $n_{t} \times 1$ vector is created, and numbers in each row are uniformly distributed between 0 and 12. $n_{t}$ is the total time steps, and in this paper, $n_{t}=1.5 \times 10^{5}$. For the time step $t$, the number in $t$-th row of this vector is assigned to the base motion frequency $f_{b}$. The amplitude of base motion $A_{b}$ is $0.0017 \mathrm{rad}$. The simulation data of the last second are shown in the following figures.

The time waveform of $f_{b}$ is provided in Fig.21, and orbits of two rotors are messy. Harmonics $1 \times$ and $2 \times$ can be observed in spectra of rotor vibrations, as shown in Fig.23. But the prominent components show no evident discipline, and should be the unstable responses of rotors under base motion with time-varying frequency. Also, some frequency bands appear in DSM along the centerline of the coupling, and their amplitudes are relatively small. By comparisons with the case in section 3.1.3, one finds that random pitch base motion has a stronger effect on the rotor vibrations than DSM.

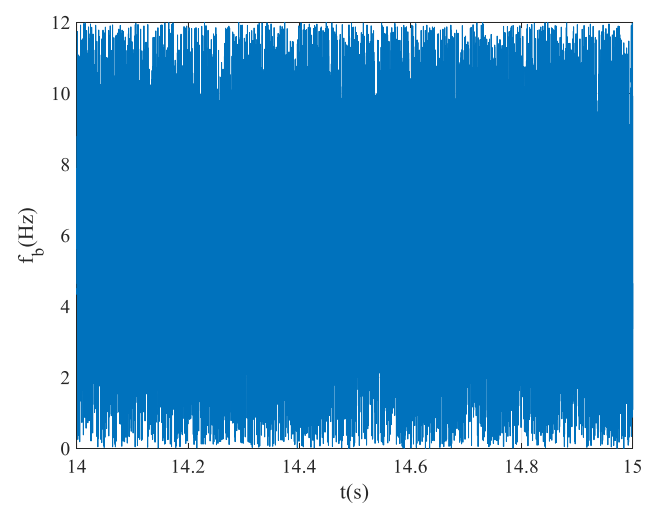

Fig.21 Time waveform of $f_{b}$

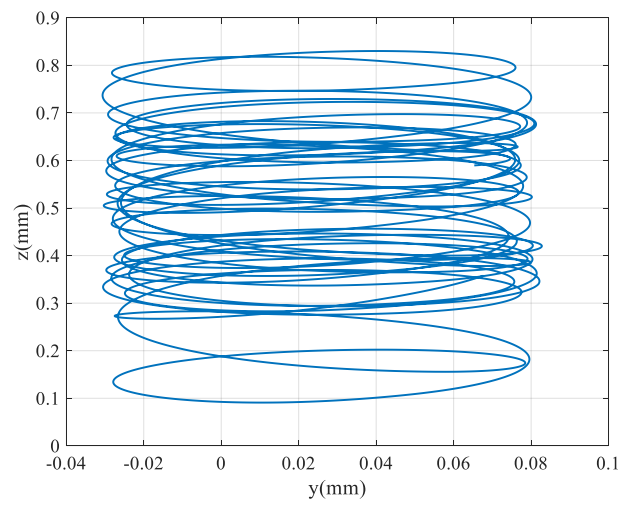

(a)

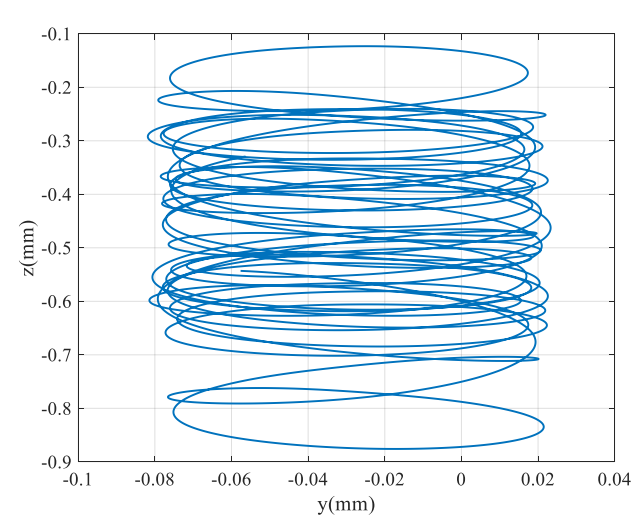

(b)

Fig.22 Orbits of (a) engine rotor and (b) generator rotor
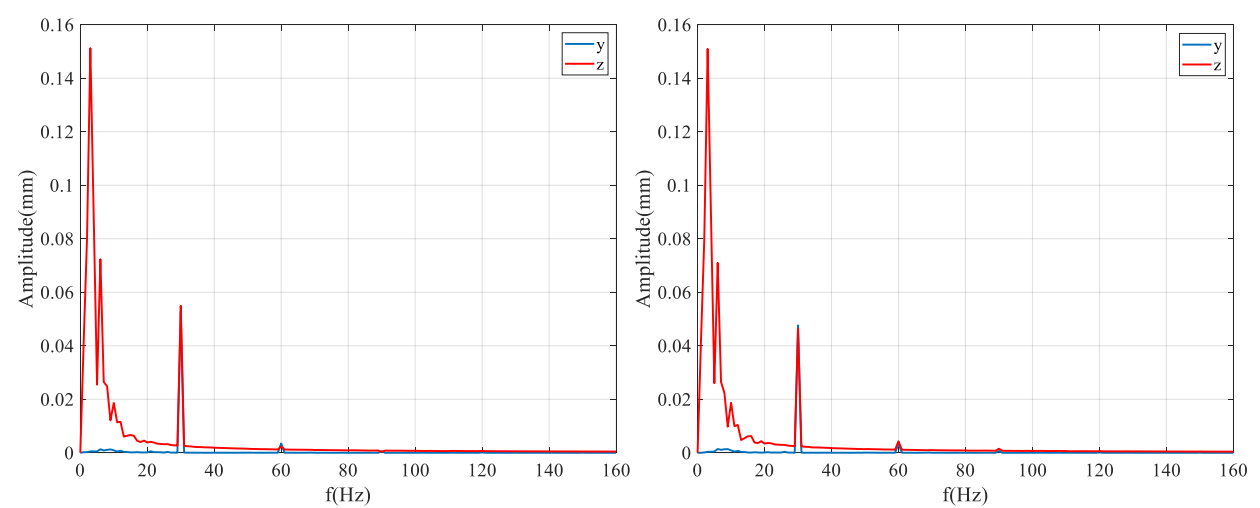
Fig.23 Spectra of horizontal and vertical vibrations of

(a) the node 13 in engine rotor and (b) the node 1 in generator rotor

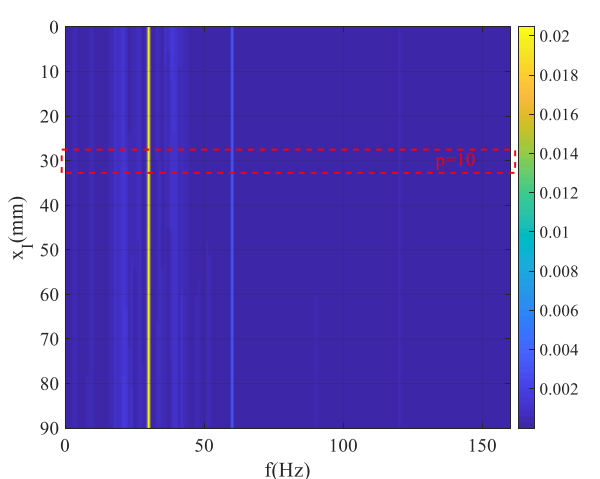

(a)

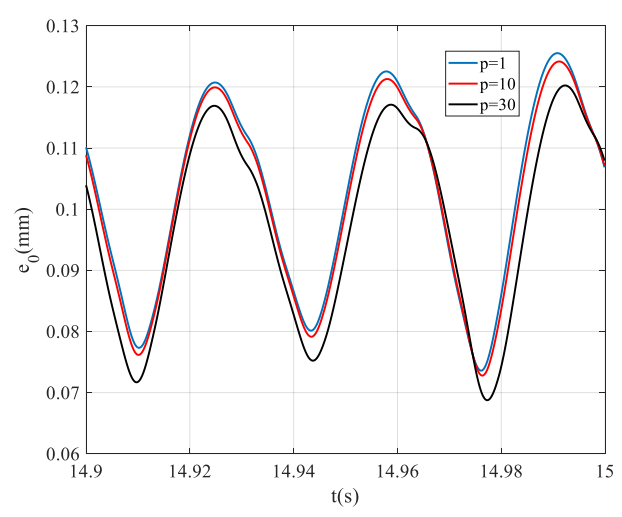

(b)

Fig.24 (a) DSM amplitude versus the frequency along the centerline of the coupling

(b) Time waveform of DSM at given position

\section{Conclusions}

A three-dimensional dynamic model of the powerpack is developed for a DMU vehicle, including the public framework, diesel engine, electric generator and rotors, under car body base motions and Dynamic Spatial Misalignment of elastic coupling. The dynamic responses of dynamic-spatially-misaligned rotors inside the engine and generator with deterministic and random base motions are investigated, which lead to following new understandings:

(1) Base motions in lateral, bounce, roll, pitch and yaw direction can bring additional vibration into the rotor system, the modulation effects of which can be observed when the amplitude of base motion is large, and effects of the latter three are more evident;

(2) Dynamic responses of the misaligned rotors under base motions in lateral and bounce direction share similar characteristics, and they are also alike for pitch, yaw and roll ones;

(3) DSM along the centerline of the elastic coupling is no longer identical all the time during rotation due to base motions and can vary hugely in some extreme cases;

(4) DSM is more sensitive to base motions than rotor vibrations. The frequency component of the base motion frequency may not appear when the amplitude is small, however DSM will be severely modulated when the base motion reaches a relatively large amplitude;

(5) Rotor vibrations are more easily affected by random base motion in pitch direction than DSM.

Those key findings provide a theoretical basis for investigations on dynamic-spatially-misaligned rotors under base motions and structural vibrations, such as in an electric transmission powerpack. Each degree of freedom of the car body base motions were considered in isolation in this paper, at the same time the diesel engine and the electric generator share same structural parameters for simplicity.

\section{Acknowledgements}

This work is supported by the Natural Science Foundation of China through the grants (51575378 and 11972245). Kun Wu (CSC No. 201906250020) was supported by the China Scholarship Council for one- 
year study in University of Huddersfield. The authors declared that they have no conflicts of interest to this work.

\section{Appendix A}

Length parameters in Section 2.2.1

\begin{tabular}{|c|c|c|}
\hline Parameter & Physical meaning & Value \\
\hline$l_{l}(\mathrm{~mm})$ & $\begin{array}{l}\text { Vertical distance between the gravity center of the public } \\
\text { framework and left/right } y \text {-direction first stage isolators }\end{array}$ & 275 \\
\hline $\begin{array}{l}l_{2, e / g} \\
(\mathrm{~mm})\end{array}$ & $\begin{array}{l}\text { Vertical distance between the gravity center of the } \\
\text { engine/generator and left/right } y \text {-direction first stage isolators }\end{array}$ & 300 \\
\hline$l_{3, i}(\mathrm{~mm})$ & $\begin{array}{l}\text { Longitudinal distance between the gravity center of the } \\
\text { public framework and the } i \text {-th } y \text {-direction first stage isolators }\end{array}$ & $\begin{array}{l}1400(i=1 \\
\text { or } 4) \\
\text { or } 200(i=2 \\
\text { or } 3)\end{array}$ \\
\hline $\begin{array}{l}l_{4, e / g} \\
(\mathrm{~mm})\end{array}$ & $\begin{array}{l}\text { Longitudinal distance between the gravity center of the } \\
\text { engine/generator and the } i \text {-th } y \text {-direction first stage isolators } \\
\qquad(i=1 \text { or } 2 \text { when } e, i=3 \text { or } 4 \text { when } g)\end{array}$ & 600 \\
\hline$l_{5}(\mathrm{~mm})$ & $\begin{array}{l}\text { Horizontal distance between the gravity center of the public } \\
\text { framework and left/right } z \text {-direction first stage isolators }\end{array}$ & 500 \\
\hline $\begin{array}{l}l_{6, e / g} \\
(\mathrm{~mm})\end{array}$ & $\begin{array}{l}\text { Horizontal distance between the gravity center of the } \\
\text { engine/generator and left/right } z \text {-direction first stage isolators }\end{array}$ & 500 \\
\hline$l_{7, i}(\mathrm{~mm})$ & $\begin{array}{l}\text { Longitudinal distance between the gravity center of the } \\
\text { public framework and the } i \text {-th } z \text {-direction first stage isolators }\end{array}$ & $\begin{array}{l}1400(i=1 \\
\text { or } 4) \\
\text { or } 200(i=2 \\
\text { or } 3)\end{array}$ \\
\hline $\begin{array}{l}l_{8, e / g} \\
(\mathrm{~mm})\end{array}$ & $\begin{array}{l}\text { Longitudinal distance between the gravity center of the } \\
\text { engine/generator and the } i \text {-th } z \text {-direction first stage isolators } \\
\qquad(i=1 \text { or } 2 \text { when } e, i=3 \text { or } 4 \text { when } g)\end{array}$ & 600 \\
\hline$l_{9}(\mathrm{~mm})$ & $\begin{array}{l}\text { Vertical distance between the gravity center of the car body } \\
\text { and left/right } y \text {-direction second stage isolators }\end{array}$ & 300 \\
\hline$l_{10}(\mathrm{~mm})$ & $\begin{array}{l}\text { Vertical distance between the gravity center of the public } \\
\text { framework and left/right } y \text {-direction second stage isolators }\end{array}$ & 275 \\
\hline$l_{11}(\mathrm{~mm})$ & $\begin{array}{l}\text { Longitudinal distance between the gravity center of the car } \\
\text { body and the } k \text {-th } y \text {-direction second stage isolators }\end{array}$ & 1400 \\
\hline$l_{12}(\mathrm{~mm})$ & $\begin{array}{l}\text { Longitudinal distance between the gravity center of the } \\
\text { public framework and the } k \text {-th } y \text {-direction second stage isolators }\end{array}$ & 1400 \\
\hline$l_{13}(\mathrm{~mm})$ & $\begin{array}{l}\text { Horizontal distance between the gravity center of the car } \\
\text { body and left/right } z \text {-direction second stage isolators }\end{array}$ & 850 \\
\hline
\end{tabular}




\begin{tabular}{|c|c|c|}
\hline$l_{14}(\mathrm{~mm})$ & $\begin{array}{l}\text { Horizontal distance between the gravity center of the public } \\
\text { framework and left/right } z \text {-direction second stage isolators }\end{array}$ & 850 \\
\hline$l_{15}(\mathrm{~mm})$ & $\begin{array}{l}\text { Longitudinal distance between the gravity center of the car } \\
\text { body and the } k \text {-th } z \text {-direction second stage isolators }\end{array}$ & 1400 \\
\hline$l_{16}(\mathrm{~mm})$ & $\begin{array}{l}\text { Longitudinal distance between the gravity center of the } \\
\text { public framework and the } k \text {-th } z \text {-direction second stage isolators }\end{array}$ & 1400 \\
\hline$l_{17}(\mathrm{~mm})$ & $\begin{array}{l}\text { Longitudinal distance between the gravity center of the } \\
\text { engine and the } m \text {-th } y \text {-direction engine rotor support }\end{array}$ & 500 \\
\hline$l_{18}(\mathrm{~mm})$ & $\begin{array}{l}\text { Longitudinal distance between the gravity center of the } \\
\text { engine and the } m \text {-th } z \text {-direction engine rotor support }\end{array}$ & 500 \\
\hline$l_{19}(\mathrm{~mm})$ & $\begin{array}{l}\text { Longitudinal distance between the gravity center of the } \\
\text { generator and the } n \text {-th } y \text {-direction generator rotor support }\end{array}$ & 500 \\
\hline$l_{20}(\mathrm{~mm})$ & $\begin{array}{l}\text { Longitudinal distance between the gravity center of the } \\
\text { generator and the } n \text {-th } z \text {-direction generator rotor support }\end{array}$ & 500 \\
\hline
\end{tabular}

\section{Appendix B}

In Equation (24), $M$ is a diagonal matrix, and $M=\operatorname{diag}\left(M_{p f}, M_{p f}, J_{p f x}, J_{p f y}, J_{p f z}, M_{e}, M_{e}, J_{e x}, J_{e y}, J_{e z}, M_{g}, M_{g}\right.$, $\left.J_{g x}, J_{g y}, J_{g z}\right) . Q$ is a $15 \times 1$ vector, and $Q=\left(Y_{p f}, Z_{p f}, \varphi_{p f}, \beta_{p f}, \psi_{p f}, Y_{e}, Z_{e}, \varphi_{e}, \beta_{e}, \psi_{e}, Y_{g}, Z_{g}, \varphi_{g}, \beta_{g}, \psi_{g}\right)^{\mathrm{T}}$.

$K$ is a $15 \times 15$ matrix, and for the first row, $K_{1,1}=4\left(2 K_{\text {fiy }}+K_{\text {siy }}\right), K_{1,3}=-4\left(2 K_{\text {fiy }} l_{1}-K_{\text {siy }} l_{10}\right)$, $K_{1,5}=2 K_{f i y}\left(l_{3,1}+l_{3,2}-l_{3,3}-l_{3,4}\right) \quad, \quad K_{1,6}=-4 K_{f i y} \quad, \quad K_{1,8}=-4 K_{f i y} l_{2, e} \quad, \quad K_{1,11}=-4 K_{f i y} \quad$, $K_{1,13}=-4 K_{f i y} l_{2, g}$; for the second row, $K_{2,2}=4\left(2 K_{f i z}+K_{s i z}\right), K_{2,4}=-2 K_{f i z}\left(l_{7,1}+l_{7,2}-l_{7,3}-l_{7,4}\right)$, $K_{2,7}=-4 K_{f i z} \quad, \quad K_{2,12}=-4 K_{f i z} \quad ; \quad$ for the third row, $K_{3,1}=-4\left(2 K_{f i y} l_{1}-K_{s i y} l_{10}\right)$, $K_{3,3}=4\left(2 K_{f i y} l_{1}^{2}+2 K_{f i z} l_{5}^{2}+K_{s i y} l_{10}^{2}+K_{s i z} l_{14}^{2}\right), K_{3,5}=-2 K_{f i y} l_{1}\left(l_{3,1}+l_{3,2}-l_{3,3}-l_{3,4}\right), K_{3,6}=4 K_{f i y} l_{1}$, $K_{3,8}=4\left(K_{f i y} l_{1} l_{2, e}-K_{f i z} l_{5} l_{6, e}\right), K_{3,11}=4 K_{f i y} l_{1}, K_{3,13}=4\left(K_{f i y} l_{1} l_{2, g}-K_{f i z} l_{5} l_{6, g}\right)$; for the fourth row, $K_{4,2}=-2 K_{f i z}\left(l_{7,1}+l_{7,2}-l_{7,3}-l_{7,4}\right) \quad, \quad K_{4,4}=2\left[K_{f i z}\left(l_{7,1}^{2}+l_{7,2}^{2}+l_{7,3}^{2}+l_{7,4}^{2}\right)+2 K_{s i z} l_{16}^{2}\right] \quad$, $K_{4,7}=2 K_{f i z}\left(l_{7,1}+l_{7,2}\right) \quad, \quad K_{4,9}=-2 K_{f i z}\left(l_{7,1}-l_{7,2}\right) l_{8, e} \quad, \quad K_{4,12}=-2 K_{f i z}\left(l_{7,3}+l_{7,4}\right) \quad$, $K_{4,14}=2 K_{f i z}\left(l_{7,3}-l_{7,4}\right) l_{8, g} \quad ; \quad$ for the fifth row, $K_{5,1}=2 K_{f i y}\left(l_{3,1}+l_{3,2}-l_{3,3}-l_{3,4}\right)$, $K_{5,5}=2\left[K_{f i y}\left(l_{3,1}^{2}+l_{3,2}^{2}+l_{3,3}^{2}+l_{3,4}^{2}\right)+2 K_{s i y} l_{12}^{2}\right] \quad, \quad K_{5,3}=-2 K_{f i y} l_{1}\left(l_{3,1}+l_{3,2}-l_{3,3}-l_{3,4}\right) \quad$, $K_{5,6}=-2 K_{f i y}\left(l_{3,1}+l_{3,2}\right) \quad, \quad K_{5,10}=-2 K_{f i y}\left(l_{3,1}-l_{3,2}\right) l_{4, e} \quad, \quad K_{5,8}=-2 K_{f i y} l_{2, e}\left(l_{3,1}+l_{3,2}\right) \quad$, $K_{5,11}=2 K_{f i y}\left(l_{3,3}+l_{3,4}\right), K_{5,13}=2 K_{f i y} l_{2, g}\left(l_{3,3}+l_{3,4}\right), K_{5,15}=2 K_{f i y}\left(l_{3,3}-l_{3,4}\right) l_{4, g}$; for the sixth row, $K_{6,1}=-4 K_{f i y}, K_{6,3}=4 K_{f i y} l_{1}, K_{6,5}=-2 K_{f i y}\left(l_{3,1}+l_{3,2}\right), K_{6,6}=2\left(2 K_{f i y}+K_{e s y}\right), K_{6,8}=4 K_{f i y} l_{2, e}$; for the seventh row, $K_{7,2}=-4 K_{f i z}, K_{7,4}=2 K_{f i z}\left(l_{7,1}+l_{7,2}\right), K_{7,7}=2\left(2 K_{f i z}+K_{e s z}\right)$; for the eighth row, 


$$
\begin{aligned}
& K_{8,1}=-4 K_{f i y} l_{2, e}, \quad K_{8,3}=4\left(K_{f i y} l_{1} l_{2, e}-K_{f i z} l_{5} l_{6, e}\right), \quad K_{8,5}=-2 K_{f i y} l_{2, e}\left(l_{3,1}+l_{3,2}\right), \quad K_{8,6}=4 K_{f i y} l_{2, e} \text {, } \\
& K_{8,8}=4\left(K_{f i y} l_{2, e}^{2}+K_{f i z} l_{6, e}^{2}\right) \quad ; \quad \text { for } \quad \text { the ninth } \quad \text { row, } K_{9,4}=-2 K_{f i z}\left(l_{7,1}-l_{7,2}\right) l_{8, e} \text {, } \\
& K_{9,9}=2\left(2 K_{f i z} l_{8, e}^{2}+K_{e s z} l_{18}^{2}\right) \quad ; \quad \text { for the } 10 \text { th } \quad \text { row, } K_{10,5}=-2 K_{f i y}\left(l_{3,1}-l_{3,2}\right) l_{4, e} \text {, } \\
& K_{10,10}=2\left(2 K_{f i y} l_{4, e}^{2}+K_{e s y} l_{17}^{2}\right) \quad ; \quad \text { for } \quad \text { the } 11 \text { th } \text { row, } K_{11,1}=-4 K_{f i y} \quad, \quad K_{11,3}=4 K_{f i y} l_{1} \text {, } \\
& K_{11,5}=2 K_{f y}\left(l_{3,3}+l_{3,4}\right), K_{11,11}=2\left(2 K_{f i y}+K_{g s y}\right), \quad K_{11,13}=4 K_{f y} l_{2, g} ; \text { for the } 12 \text { th row, } \\
& K_{12,2}=-4 K_{f i z} \quad, \quad K_{12,4}=2 K_{f i z}\left(l_{7,3}+l_{7,4}\right) \quad, \quad K_{12,12}=2\left(2 K_{f i z}+K_{g s z}\right) ; \text { for the 13th row, } \\
& K_{13,1}=-4 K_{f i y} l_{2, g}, K_{13,3}=4\left(K_{f i y} l_{1} l_{2, g}-K_{f i z} l_{5} l_{6, g}\right), K_{13,5}=2 K_{f i y} l_{2, g}\left(l_{3,3}+l_{3,4}\right), K_{13,11}=4 K_{f i z} l_{2, g} \text {, } \\
& K_{13,13}=4\left(K_{f i y} l_{2, g}^{2}+K_{f i z} l_{6, g}^{2}\right) \quad ; \quad \text { for } \quad \text { the } 14 \text { th } \quad \text { row, } K_{14,4}=2 K_{f i z}\left(l_{7,3}-l_{7,4}\right) l_{8, g} \text {, } \\
& K_{14,14}=2\left(2 K_{f i z} l_{8, g}^{2}+K_{g s z} l_{20}^{2}\right) \quad ; \quad \text { for the } 15 \text { th } \text { row, } K_{15,5}=2 K_{f i z}\left(l_{3,3}-l_{3,4}\right) l_{4, g} \text {, } \\
& K_{15,15}=2\left(2 K_{f i y} l_{4, g}^{2}+K_{g s y} l_{19}^{2}\right) \text {. The rest elements in } K \text { are zero. }
\end{aligned}
$$

$C$ is a $15 \times 15$ matrix, and is identical with the stiffness matrix $K$ as long as $K_{f i y}, K_{f i z}, K_{s i y}, K_{s i z}, K_{e s y}, K_{e s z}$, $K_{g s y}$ and $K_{g s z}$ in $K$ are replaced with $C_{f i y}, C_{f i z}, C_{s i y}, C_{s i z}, C_{e s y}, C_{e s z}, C_{g s y}$ and $C_{g s z}$ respectively.

And the external excitation $F$ is a $15 \times 1$ vector, and

$$
F=\left[\begin{array}{c}
4 K_{s i y}\left(Y_{c}-l_{9} \varphi_{c}\right)+4 C_{s i y}\left(\dot{Y}_{c}-l_{9} \dot{\varphi}_{c}\right) \\
4 K_{s i y} Z_{c}+4 C_{s i y} \dot{Z}_{c} \\
4 K_{s i y} l_{10} Y_{c}-4\left(K_{s i y} l_{9} l_{10}-K_{s i z} l_{13} l_{14}\right) \dot{\varphi}_{c}+4 C_{s i y} l_{10} \dot{Y}_{c}-4\left(C_{s i y} l_{9} l_{10}-C_{s i z} l_{13} l_{14}\right) \dot{\varphi}_{c} \\
4 K_{s i z} l_{15} l_{16} \beta_{c}+4 C_{s i z} l_{15} l_{16} \dot{\beta}_{c} \\
4 K_{s i y} l_{11} l_{12} \psi_{c}+4 C_{s i y} l_{11} l_{12} \dot{\psi}_{c} \\
K_{e s y}\left(Y_{e 1}+Y_{e 2}\right)+C_{e s x}\left(\dot{Y}_{e 1}+\dot{Y}_{e 2}\right) \\
K_{e s z}\left(Z_{e 1}+Z_{e 2}\right)+C_{e s z}\left(Z_{e 1}+\dot{Z}_{e 2}\right) \\
0 \\
-K_{e s z} l_{18}\left(Z_{e 1}-Z_{e 2}\right)-C_{e s z} l_{18}\left(\dot{Z}_{e 1}-\dot{Z}_{e 2}\right) \\
K_{e s y} l_{17}\left(Y_{e 1}-Y_{e 2}\right)+C_{e s z} l_{17}\left(\dot{Y}_{e 1}-\dot{Y}_{e 2}\right) \\
K_{g s y}\left(Y_{g 1}+Y_{g 2}\right)+C_{g s y}\left(\dot{Y}_{g 1}+\dot{Y}_{g 2}\right) \\
K_{g s z}\left(Z_{g 1}+Z_{g 2}\right)+C_{g s z}\left(\dot{Z}_{g 1}+\dot{Z}_{g 2}\right) \\
0 \\
-K_{g s z} l_{20}\left(Z_{g 1}-Z_{g 2}\right)-C_{g s z} l_{20}\left(\dot{Z}_{g 1}-\dot{Z}_{g 2}\right) \\
K_{g s y} l_{19}\left(Y_{g 1}-Y_{g 2}\right)+C_{g s y} l_{19}\left(\dot{Y}_{g 1}-\dot{Y}_{g 2}\right)
\end{array}\right] .
$$

\section{References}

[1] C.A. Messa, Comparison of emissions from light rail transit, electric commuter rail, and diesel multiple units, Journal of the Transportation Research Board, 1955 (2006) 8.

[2] S. Schmid, K. Ebrahimi, A. Pezouvanis, W. Commerell, Model-based comparison of hybrid propulsion systems for railway diesel multiple units, International Journal of Rail Transportation, 6 (2017) 16-37.

[3] Z. Chen, W. Zhai, K. Wang, A locomotive-track coupled vertical dynamics model with gear transmissions, Vehicle System Dynamics, 55 (2016) 244-267. 
[4] T. Zhang, Z. Chen, W. Zhai, K. Wang, Establishment and validation of a locomotive-track coupled spatial dynamics model considering dynamic effect of gear transmissions, Mechanical Systems and Signal Processing, 119 (2019) 328-345.

[5] W. Wang, Y. Zhang, H. Ouyang, An iterative method for solving the dynamic response of railway vehicle-track coupled systems based on prediction of wheel-rail forces, Engineering Structures, 151 (2017) 297-311.

[6] G. Gu, J. Choi, The dynamic response of rail support, Vehicle System Dynamics, 51 (2013) 798-820.

[7] J. Huo, H. Wu, D. Zhu, W. Sun, L. Wang, J. Dong, The rigid-flexible coupling dynamic model and response analysis of bearing-wheel-rail system under track irregularity, Proceedings of the Institution of Mechanical Engineers, Part C: Journal of Mechanical Engineering Science, 232 (2017) 3859-3880.

[8] L. Chen, J. Wang, Q. Han, F. Chu, Nonlinear dynamic modeling of a simple flexible rotor system subjected to time-variable base motions, Journal of Sound and Vibration, 404 (2017) 58-83.

[9] A.S. Lee, B.O. Kim, Y.-C. Kim, A finite element transient response analysis method of a rotor-bearing system to base shock excitations using the state-space Newmark scheme and comparisons with experiments, Journal of Sound and Vibration, 297 (2006) 595-615.

[10] X. Qiu, Q. Han, F. Chu, Dynamic modeling and analysis of the planetary gear under pitching base motion, International Journal of Mechanical Sciences, 141 (2018) 31-45.

[11] F.M.A. El-Saeidy, F. Sticher, Dynamics of a Rigid Rotor Linear/Nonlinear Bearings System Subject to Rotating Unbalance and Base Excitations, Journal of Vibration and Control, 16 (2009) 403-438.

[12] H. Phadatare, B. Choudhary, B. Pratiher, Evaluation of nonlinear responses and bifurcation of a rotor-bearing system mounted on moving platform, Nonlinear Dynamics, 90 (2017) 493-511.

[13] M. Li, L. Yu, Analysis of the Coupled Lateral Torsional Vibration of a Rotor-Bearing System with a Misaligned Gear Coupling, Journal of Sound and Vibration, 243 (2001) 283-300.

[14] Y. Guo, S. Lambert, R. Wallen, R. Errichello, J. Keller, Theoretical and experimental study on gear-coupling contact and loads considering misalignment, torque, and friction influences, Mechanism and Machine Theory, 98 (2016) 242-262.

[15] H.H. El-Mongy, Y.K. Younes, Vibration analysis of a multi-fault transient rotor passing through sub-critical resonances, Journal of Vibration and Control, 24 (2017) 2986-3009.

[16] Z. Liu, K. Wu, Q. Ding, J.X. Gu, Engine Misfire Diagnosis Based on the Torsional Vibration of the Flexible Coupling in a Diesel Generator Set: Simulation and Experiment, Journal of Vibration Engineering \& Technologies, (2019).

[17] Z. Liu, K. Wu, Z. Ma, Q. Ding, Vibration Analysis of a Rotating Flywheel/Flexible Coupling System with Angular Misalignment and Rubbing Using Smoothed Pseudo Wigner-Ville Distributions, Journal of Vibration Engineering \& Technologies, (2019).

[18] V.J. Lučanin, G.Ž. Simić, D.D. Milković, N.L. Ćuprić, S.D. Golubović, Calculated and experimental analysis of cause of the appearance of cracks in the running bogie frame of diesel multiple units of Serbian railways, Engineering Failure Analysis, 17 (2010) 236-248.

[19] B. Han, Q. Ding, Forced responses analysis of a rotor system with squeeze film damper during flight maneuvers using finite element method, Mechanism and Machine Theory, 122 (2018) 233-251. 